\title{
Design and Synthesis of Functional Silsesquioxane-Based Hybrids by Hydrolytic Condensation of Bulky Triethoxysilanes
}

\author{
Hideharu Mori \\ Department of Polymer Science and Engineering, Graduate School of Science and Engineering, Yamagata University, 4-3-16, Jonan, \\ Yonezawa 992-8510, Japan \\ Correspondence should be addressed to Hideharu Mori, h.mori@yz.yamagata-u.ac.jp
}

Received 12 July 2012; Accepted 15 September 2012

Academic Editor: Kimihiro Matsukawa

Copyright ( $(2012$ Hideharu Mori. This is an open access article distributed under the Creative Commons Attribution License, which permits unrestricted use, distribution, and reproduction in any medium, provided the original work is properly cited.

This paper presents a short overview of recent advances in the design and synthesis of organic-inorganic hybrids using silsesquioxane-based nanoparticles having nanometer size, relatively narrow size distribution, high functionalities, and various characteristic features, mainly focusing on our recent researches related to the subject. A highlight of this paper is the water-soluble silsesquioxane-based nanoparticles, including hydroxyl-functionalized and cationic silsesquioxanes, which were synthesized via the one-step condensation of the bulky triethoxysilane precursors. The design and synthesis of $\mathrm{R}-\mathrm{SiO}_{1.5} / \mathrm{SiO} \mathrm{O}_{2}$ and $\mathrm{R}-\mathrm{SiO} \mathrm{I}_{1.5} / \mathrm{TiO} \mathrm{O}_{2}$ hybrids by hydrolytic cocondensation of a triethoxysilane precursor and metal alkoxides are briefly introduced. This paper also deals with recent results in stimuli-responsive hybrids based on the water-soluble silsesquioxane nanoparticles and fluorinated and amphiphilic silsesquioxane hybrids.

\section{Introduction}

The silsesquioxane family is now recognized to have an enormous potential as a building block for various advanced materials, and their applications can be found in the areas of catalysis, coordination chemistry, and material science, such as organic-inorganic nanocomposites [1-9]. Silsesquioxane is a family of compounds characterized by a ratio of 1.5 between the silicon and oxygen atoms [4], and the structures can be expressed in the general formula: $\left(\mathrm{R}-\mathrm{SiO}_{1.5}\right)_{n}(n=$ even number) [1]. In particular, much interest has been paid to cubic $\mathrm{T}_{8}$ silsesquioxane $\left(\mathrm{R}-\mathrm{SiO}_{1.5}\right)_{8}$, consisting of a rigid, crystalline silica-like core that is perfectly defined spatially $(0.5-0.7 \mathrm{~nm})$ and that can be linked covalently to eight $\mathrm{R}$ groups $[10,11]$, because of their possible applications in optics, electronics, engineering, and biosciences.

Although some $\mathrm{T}_{8}$ compounds are commercially available, the synthesis of polyhedral oligomeric silsesquioxane (also known as $\mathrm{T}_{8}$ silsesquioxane or POSS) is plagued by relatively low yields of multistage syntheses and timeconsuming procedures. One alternative to exploit them for practical applications is to use a more easily accessible mixture of silsesquioxanes. The hydrolysis and polycondensation of substituted alkoxysilanes, $\mathrm{R}-\mathrm{Si}\left(\mathrm{OR}^{\prime}\right)_{3}$, containing a nonhydrolyzable $\mathrm{Si}-\mathrm{C}$ bond or chlorosilanes are known to be a representative method to afford a variety of silsesquioxanes with various substituent groups and cage structures [2-4]. In the synthesis of silsesquioxanes via hydrolytic condensation of $\mathrm{R}-\mathrm{Si}\left(\mathrm{OR}^{\prime}\right)_{3}$, it is known that the reactions and the resulting structures are influenced by many factors, such as the nature of the $\mathrm{R}^{\prime}$ and $\mathrm{R}$ groups, solvent, concentration, addition rate, quality of water, temperature, $\mathrm{pH}$, and reaction time $[3,4]$. Among them, water related with the hydrolysis reaction to give trisilanol and the solvent related with the solubilities of a precursor and resulting hybrid may play a relevant role in influencing the synthesis.

A variety of silsesquioxanes having various functional groups, different numbers of substituent groups, and cage structures has been developed. Completely condensed silsesquioxanes, $\left(\mathrm{R}-\mathrm{SiO}_{1.5}\right)_{n}$ with $n=4,6,8,10$, and 12 , have been synthesized and characterized [4]. Completely condensed structures, $\left(\mathrm{R}-\mathrm{SiO}_{1.5}\right)_{n}$ with $n>12$, are not so common, but some examples have been reported $[3,12,13]$. In addition to the fully condensed structures, $\left(\mathrm{R}-\mathrm{SiO}_{1.5}\right)_{n}$, 
$\mathrm{T}_{8}$
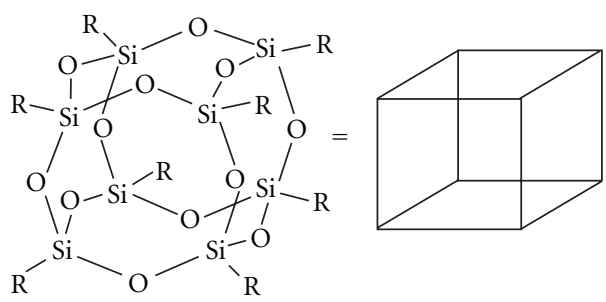

$\mathrm{T}_{8}(\mathrm{OH})_{4}$

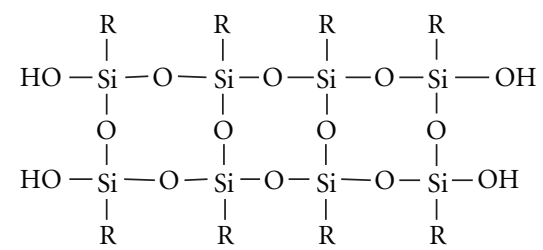

$\mathrm{T}_{8}(\mathrm{OH})_{2}$

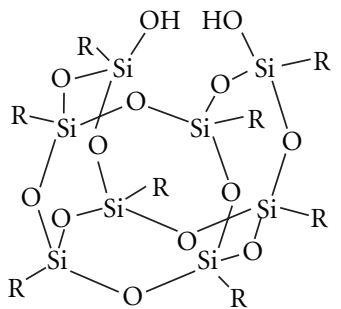

$\mathrm{T}_{14}$

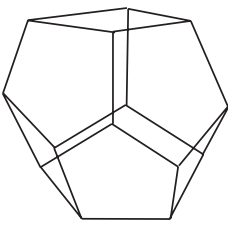

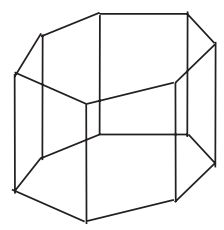

$\mathrm{T}_{12}$

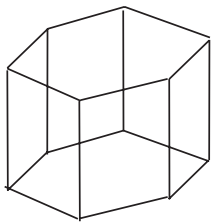

$\mathrm{T}_{16}$

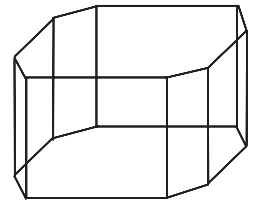

Figure 1: Schematic representation of various structures, ladder $\left(\mathrm{T}_{8}(\mathrm{OH})_{4}\right)$, partially cage $\left(\mathrm{T}_{8}(\mathrm{OH})_{2}\right)$, and cage $\left(\mathrm{T}_{8}-\mathrm{T}_{16}\right)$ structures.

which is denoted as $\mathrm{T}_{n}$ ( $n=$ even number), incompletely condensed structures containing $\mathrm{Si}-\mathrm{OH}$ groups are known, which have generic formula; $\left[\mathrm{R}-\mathrm{SiO}_{1.5-x}(\mathrm{OH})_{2 x}\right]_{n}$ or $\mathrm{T}_{n}(\mathrm{OH})_{m}[1,4,14]$. The structures include perfect polyhedra, incompletely condensed polyhedra (species with 1-3 OH per molecule), ladder-type structure (species with 4 $\mathrm{OH}$ per molecule), open structure (species with more than $5 \mathrm{OH}$ per molecule), linear structure, and all their possible combinations. Examples of possible structures are shown in Figure 1.

Preferable formation of cubic $T_{8}$ species over the $T_{10}$, $\mathrm{T}_{12}$, and other fully condensed species is known to be due to the stability of the $\mathrm{Si}_{4} \mathrm{O}_{4}$ ring structures. Even if a variety of cubic silsesquioxanes having various functional groups has been developed by the hydrolysis/condensation process, it does have certain inherent disadvantages, such as long reaction times, up to three months in some cases, and low yields less than $50 \%$ [5]. The low yield is one of the most important problems to afford cubic $\mathrm{T}_{8}$ species by the hydrolysis/condensation. This is mainly attributed to the formation of the mixtures of the fully condensed products with byproducts of ladder and other nonpolyhedral silsesquioxanes and formation of oligomeric products having higher contents of silicon atoms, such as $\mathrm{T}_{10}, \mathrm{~T}_{12}$. The difficulty in the separation of the desired cubic $\mathrm{T}_{8}$ species from the byproducts is another reason for low yields.

Organic-inorganic hybrid nanoparticles have attracted a great deal of attention due to their potential applications in a wide range of fields. Further advances of such organic-inorganic nanocomposite materials require finetuning of the sizes, structures, compositions, topologies, and spatial assembly of individual constitutes and their interfaces. Several efforts have been directed at the preparation of novel colloids and nanoparticles based on the hydrolytic condensation of monosilanes, and the resulting products are often called polysilsesquioxanes colloids or polyorganosiloxane nanoparticles. For example, Bronstein et al. reported the synthesis of a new family of polysilsesquioxanes colloids based by hydrolytic condensation of $\mathrm{N}$-(6-aminohexyl)aminopropyltrimethoxysilane [15]. They claimed that the well-defined colloids (30$50 \mathrm{~nm}$ ) were obtained at neutral initial $\mathrm{pH}$. The synthesis of nanoparticles of poly(phenyl/methylsilsesquioxane) was conducted by polymerization of the cohydrolyzate from a mixture of trichlorophenylsilane and trichloromethylsilane in aqueous solution [16]. By changing the initial conditions, the average size of the resultant particles could be controlled from 30 to $250 \mathrm{~nm}$ in diameter. Other examples involve the syntheses of poly(phenylsilsesquioxane)s with particle sizes from 30 to $110 \mathrm{~nm}$ by polycondensation of phenylsilanetriol formed in aqueous solution [17] and polyorganosiloxane nanoparticles by using alkylalkoxysilanes, in which methyltrimethoxysilane was used as a network-forming monomer and diethoxydimethylsilane was employed as a chain-forming monomer in the presence of the surfactant [18].

This paper highlights recent developments in the design and synthesis of organic-inorganic hybrids using silsesquioxane-based nanoparticles having nanometer size, relatively narrow size distribution, high functionalities, and various characteristic features (Figure 2). Because the synthesis of $\mathrm{T}_{8}$ silsesquioxane requires complicated and time-consuming procedures, much attention has been paid in developing facile synthetic methods for silsesquioxanebased nano-objects having uniform size and characteristic properties. This paper initially deals with the water-soluble silsesquioxane-based nanoparticles, including hydroxyl-functionalized silsesquioxanes (Figure 2(a)) and cationic silsesquioxanes (Figure 2(c)), which were synthesized via the one-step condensation of the bulky triethoxysilane precursors. An attractive feature of this system is that it makes it feasible to create a variety of hybrid materials 


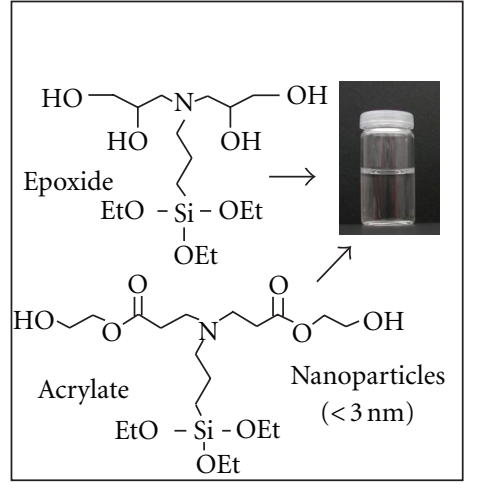

(a)

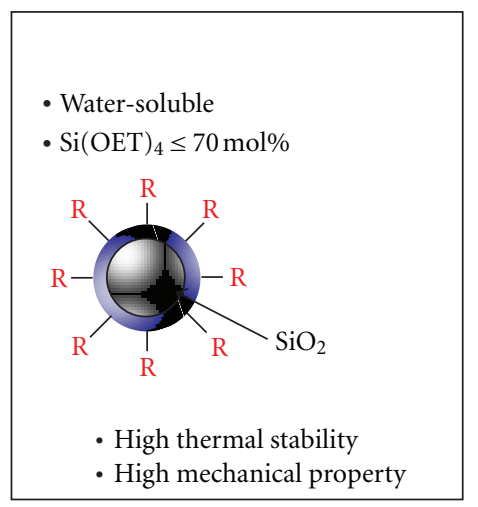

(d)

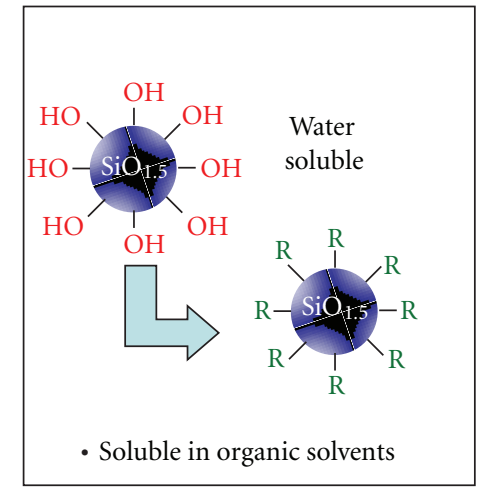

(b)

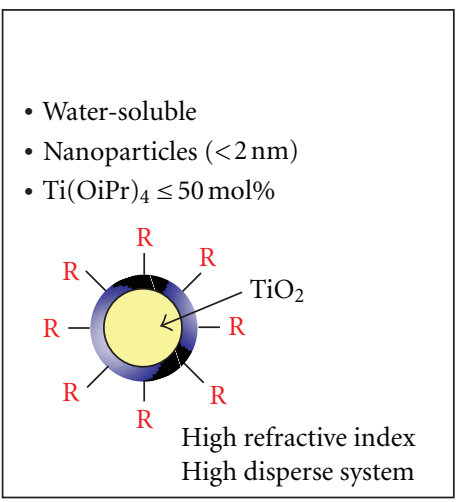

(e)

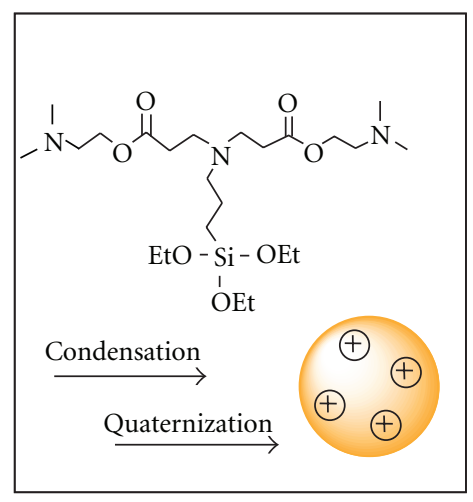

(c)

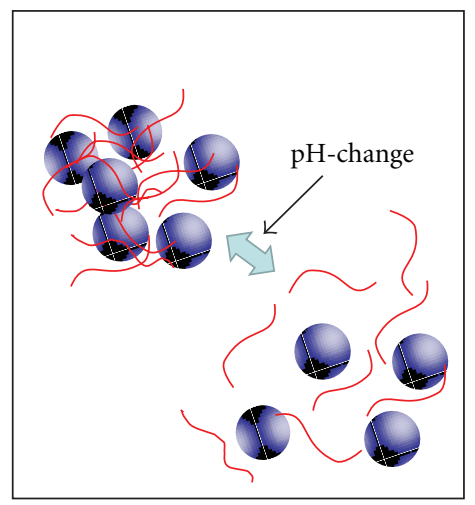

(f)

FIGURE 2: Summary of water-soluble silsesquioxane-based nanoparticles. (a) Water-soluble hybrids synthesized by hydrolytic condensation of hydroxyl-functionalized triethoxysilanes; (b) end-group modifications of the hydroxyl groups of the water-soluble hybrids; (c) cationic hybrids obtained by hydrolytic condensation, followed by quaternization; (d) $\mathrm{R}-\mathrm{SiO}_{1.5} / \mathrm{SiO}_{2}$ hybrids; (e) $\mathrm{R}-\mathrm{SiO}_{1.5} / \mathrm{TiO}_{2}$ hybrids prepared by hydrolytic cocondensation of the hydroxyl-functionalized triethoxysilane and metal alkoxides; (f) smart hybrids based on the complexation of the silsesquioxane nanoparticles and weak polyelectrolyte.

having different functional organic components through the design of appropriate triethoxysilane precursors, because various epoxy compounds and vinyl monomers can be employed as starting materials. A facile synthetic method with short synthetic steps of high yield is another advantage of this approach, an advantage which is a crucial in practical applications. Other examples involve the synthesis of $\mathrm{R}-$ $\mathrm{SiO}_{1.5} / \mathrm{SiO}_{2}$ hybrids (Figure $2(\mathrm{~d})$ ) and $\mathrm{R}-\mathrm{SiO}_{1.5} / \mathrm{TiO}_{2}$ hybrids (Figure 2(e)) by hydrolytic cocondensation of the hydroxylfunctionalized triethoxysilane precursor and metal alkoxides. The design and synthesis of stimuli-responsive hybrids based on the silsesquioxane nanoparticles (Figure 2(f)) are briefly introduced. Examples of fluorinated and amphiphilic silsesquioxane hybrids are also given (Figure 3 ).

\section{Hydroxyl-Functionalized Silsesquioxane-Based Hybrids}

Research on water-soluble metal/metal oxide nanoparticles with narrow size distributions and characteristic properties has been extensively conducted, due to their potential applications, particularly in biorelated fields. Effective use of water-soluble nanoparticles in a given application requires fine-tuning of two factors; the physical properties of the particles itself (size, topology, composition, and nature of the particle itself) and the chemical properties of their interfaces to avoid unfavorable aggregation of individual nanoparticle and to promote specific interactions with target molecules. During recent years, there has been increasing attention paid to water-soluble silsesquioxane-based materials with tunable properties and well-defined multidimensional architectures [19-23].

Water-soluble silsesquioxane-based nanoparticles (diameter $<3.0 \mathrm{~nm}$ ) were synthesized by hydrolytic condensation of hydroxyl-functionalized triethoxysilanes under mild conditions (Figure 2(a)). The first example is the synthesis of water-soluble nanoparticles by hydrolytic condensation of a functionalized precursor, N,N-di(2,3-dihydroxypropyl)aminopropyltriethoxysilane, which was prepared by addition reaction of (3-aminopropyl)triethoxysilane and glycidol (Figure 4(a)) $[24,25]$. After the solvents (methanol and ethanol) were evaporated in vacuum, the product was obtained as a glassy solid at room temperature. In addition to tertiary amino groups, the resulting nanoparticle should have hydroxyl groups on the outermost surface, which lead to water-soluble property. The resulting silsesquioxanebased nanoparticle is soluble directly in water, methanol, 


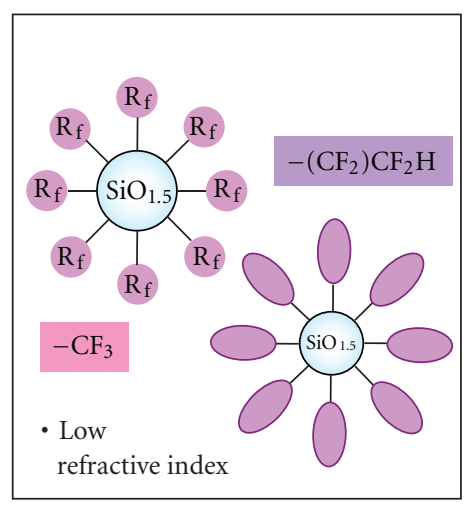

(a)

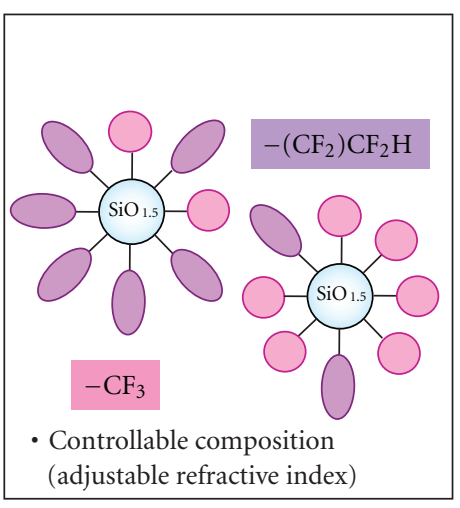

(b)

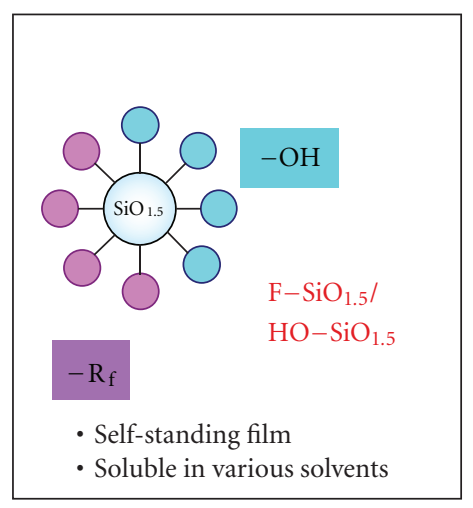

(c)

FIGURE 3: Summary of fluorinated silsesquioxane-based nanoparticles. (a) Fluorinated hybrids prepared by hydrolytic condensation of triethoxysilane precursors derived from fluoroalkyl acrylates; (b) cocondensation products obtained by hydrolytic cocondensation of TFEA-based and OFPA-based triethoxysilane precursors; (c) amphiphilic hybrids based on hydrolytic cocondensation of the hydroxylfunctionalized triethoxysilane precursor and fluorinated triethoxysilane precursors.

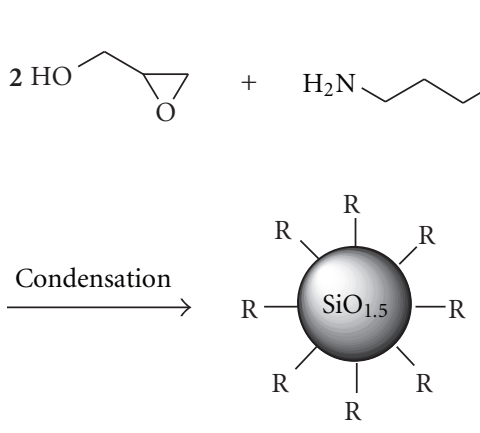

$\left(\mathrm{R}-\mathrm{SiO}_{1.5}\right)_{n^{\prime}} n>8$<smiles>[R]CCCN(CC(O)CO)CC(O)CO</smiles>

$\mathrm{EtO}-\mathrm{Si}-\mathrm{OEt}$
$\stackrel{\mathrm{O}}{\mathrm{OEt}}$

(a) Condensation of a triethoxysilane derived from glycidol

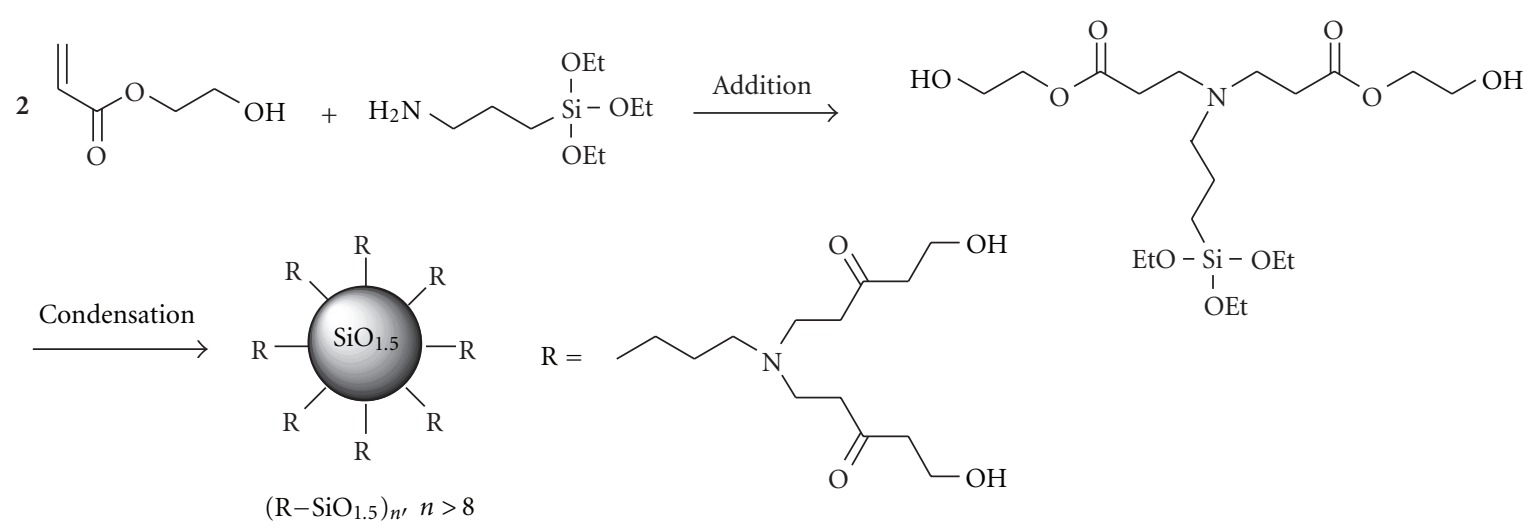

(b) Condensation of a triethoxysilane derived from 2-hydroxyethyl acrylate

FIGURE 4: Synthesis of water-soluble silsesquioxane-based nanoparticles by hydrolytic condensation of hydroxyl-functionalized triethoxysilanes.

DMF, and DMSO, while insoluble in most organic solvents, such as dichloromethane, acetone, and dioxane, and so forth. The resulting particles have relatively narrow size distribution with average particle diameter less than $3.0 \mathrm{~nm}$, as confirmed by transmission electron microscopy (TEM) and scanning force microscopy (SFM). Due to the tiny size and high functionality, the nanoparticles can be uniformly dispersed in water and behave as single dissolved molecules to form a transparent colloidal solution. MALDITOF MS analysis indicated that the product consists of 
many species having 12-18 Si atoms with different numbers of intramolecular cyclizations, and the $\mathrm{Si}-\mathrm{O}-\mathrm{C}$ bonds are formed through the reaction of $\mathrm{SiOH}$ (or $\mathrm{SiOEt}$ ) groups with the hydroxyl functionalities of an organic moiety bonded to a Si atom. The species having high number of intermolecular cyclization were predominantly detected, suggesting that product mainly consists of complete and incomplete cagelike structures. Note that most of functional groups are considered to exist on the surface of the silsesquioxane-based materials, there is a possibility for some functional groups to exist within the materials. Nevertheless, this facile synthetic method with short synthetic steps with high yield endowed the nanoparticles with characteristic properties such as high functionalities, good solubility in aqueous media, nanometer size, and narrow size distribution. The silsesquioxane-based nanoparticles with a high density of hydroxyl groups on the surface were used as functional cores for the syntheses of organic/inorganic hybrid stars via "grafting from" polymerization methods [26, 27], amphiphilic silsesquioxanes having various molar ratios of hydrophilic and hydrophobic terminal groups [28], smart nanohybrid based on the complexation with amphiphilic block copolymer micelles [29], and polyurethane-silsesquioxane hybrids [30].

Although the mechanism of the formation is not yet fully understood, the feasibility to create the nanoparticles having narrow size distribution by one step condensation of the organotriethoxysilane is of interest, as it offers the possibility of large-scale production without tedious and time-consuming process. Similar behavior was also reported by another group, in which hydrolytic condensation of triethoxysilanes bearing bulky organic substituents with hydroxyl groups produced cage-type silsesquioxane having a sharp distribution with 8,9 , and $10 \mathrm{Si}$ atoms $[31,32]$. They demonstrated that the formation of the closed structures seems to be originated by the presence of ( $\beta$-hydroxyl) tertiary amine groups in the starting organotrialkoxysilanes, in addition to the bulkiness of the organic group attached to silicon atoms $[33,34]$.

A bulky functionalized triethoxysilane precursor prepared by addition reaction of (3-aminopropyl)triethoxysilane and 2-hydroxyethyl acrylate (HEA) could be also employed for the preparation of water-soluble nanoparticles (Figure 4(b)) [35]. This can be regarded as the synthesis of a new family of the silsesquioxane-based nanoparticles having uniform size distribution and characteristic watersoluble property by hydrolytic condensation of the hydroxylfunctionalized triethoxysilane precursor. As shown in Figure 4(b), the first step is the addition reaction of aminopropyltriethoxysilane and HEA, followed by acidic condensation of the addition product to afford silsesquioxanebased nanoparticles. The condensation of the triethoxysilane precursor proceeded as a homogeneous system in methanol in the presence of $\mathrm{HF}(3.2 \%)$ at ambient temperature for $2 \mathrm{~h}$ to afford the water-soluble hybrids quantitatively. In addition to tertiary amino groups, the resulting silsesquioxane-based nanoparticles should have hydroxyl groups on the outermost surface, which leads to water soluble property. The size distribution was relatively small, and the average particle size was less than $2 \mathrm{~nm}$, as confirmed by X-ray diffraction
(XRD) and SFM measurements (Figure 5). The narrow polydispersity $\left(M_{w} / M_{n}=1.08\right)$ and a reasonable molecular weight $\left(M_{n}=3300\right)$, corresponding to species having 6-12 silicon atoms, were also confirmed by size-exclusion chromatography (SEC) measurements. For SEC measurement, the hydroxyl groups of the water-soluble silsesquioxanebased nanoparticles were converted into isobutyl ester form by esterification reaction (Figure 2(b)). The investigation of the hydrolytic condensation under various conditions suggested that the presence of the hydroxyl groups in the alkyl chain facilitates the internal cyclization, and the homogeneous reaction systems in alcohol may be prerequisite for the nanoparticle formation. In this system, the triethoxysilane precursor, $\mathrm{R}-\mathrm{Si}\left(\mathrm{OCH}_{2} \mathrm{CH}_{3}\right)_{3}, \mathrm{R}=$ $\mathrm{CH}_{2} \mathrm{CH}_{2} \mathrm{CH}_{2} \mathrm{~N}\left(\mathrm{CH}_{2} \mathrm{CH}_{2} \mathrm{COOCH}_{2} \mathrm{CH}_{2} \mathrm{OH}\right)_{2}$, has a bulky organic group attached to a silicon atom, but the position of the hydroxyl group is far from the tertiary amino group. The bulkiness of the organic group and the distance between the hydroxyl group and the tertiary amino group may have some influence on the internal cyclization, resulting in the formation of closed structures and avoidance of gelation.

In this synthetic procedure, the reaction system is homogeneous during the hydrolysis/condensation reaction, since both the precursor and the resulting silsesquioxane hybrid are soluble in methanol in the presence of a small amount of HF aqueous solution used as acidic catalyst. This is a quite different feature from conventional systems, in which the reaction is heterogeneous, because precursors containing a $\mathrm{H}$ or an alkyl chain bonded to a $\mathrm{Si}$ atom are only soluble in organic solvents. In this system, the usage of the functional triethoxysilane precursor having two hydroxyl groups and ester groups may support the formation of the functionalized silsesquioxane hybrid that has nanometer size, uniform size distribution, and good solubility in many solvents. These results suggest the feasibility of creating the silsesquioxane hybrid having a high density of chemically bonded peripheral hydroxyl groups on the outermost surface, via the one-step condensation of the bulky triethoxysilane precursor, which can be achieved through the careful choice of the organic structure and condensation conditions.

\section{Water-Soluble R-SiO ${ }_{1.5} / \mathrm{SiO}_{2}$ Hybrid Nanoparticles by Cocondensation}

Cocondensation of a trialkoxysilane and a tetraalkoxysilane compound provides organic-inorganic hybrid materials, in which thermal and mechanical properties can be manipulated by the tetraalkoxysilane content. The increase in a tetraalkoxysilane compound in the feed may lead to the formation of glassy hybrids with higher inorganic component. Further, the cocondensation can be regarded as a convenient and promising process to produce novel functional hybrids, which have inorganic silica-like properties and exhibit characteristic solubility in appropriate solvents, if the presence of a particular trialkoxysilane prevents the gelation effectively during the hydrolytic cocondensation of the mixtures. 

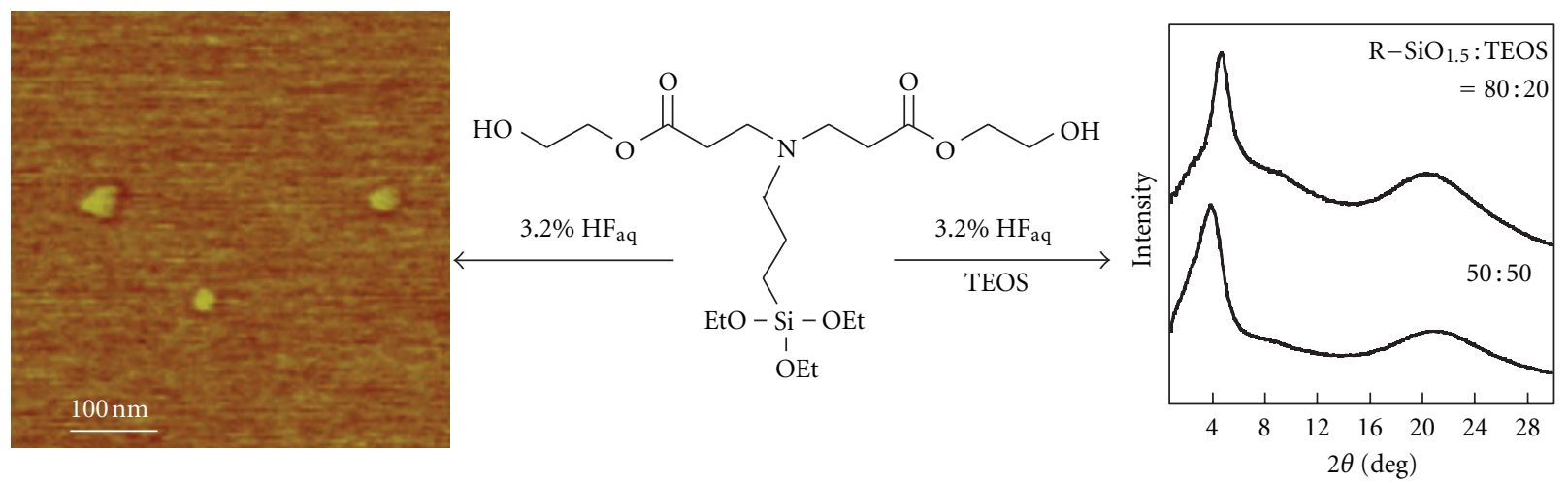

FIGURE 5: SFM height image and XRD spectra of water-soluble silsesquioxane-based nanoparticles synthesized by hydrolytic (co-)condensation of the hydroxyl-functionalized triethoxysilane precursor derived from 2-hydroxyethyl acrylate (HEA). Reprinted with permission from [35]. Copyright 2007 American Chemical Society.

The cocondensation of tetraethoxysilane (TEOS) with the hydroxyl-functionalized triethoxysilane precursor provided water-soluble nanoparticles having similar sizes (ca, $2 \mathrm{~nm}$ ) with higher thermal property, depending on the composition in the feed (Figure 6(a)) [35]. Cocondensation was carried out under different feed ratios in methanol at room temperature, and the water-soluble products were obtained in the cases of TEOS molar ratio up to $70 \%$ (Figure 2(d)). Thermal stability and the char yield were found to increase with increasing the TEOS content in the feed, as determined by thermogravimetric analysis. The isolated nanoparticles distributed homogeneously without any aggregation were visualized by SFM, when the product was prepared at TEOS/the triethoxysilane $=50 / 50 \mathrm{~mol} \%$. The formation of the nanoparticles by hydrolytic cocondensation was also confirmed by the XRD studies (Figure 5). In the cocondensation process, the content of inorganic component, solubility, thermal stability, and size of the hybrid materials could be manipulated, depending on the triethoxysilane precursor/tetraethoxysilane ratio in the feed. Another attractive feature of this system is the feasibility to create a variety of hybrid materials, because various metal alkoxides can be employed as starting materials.

\section{Water-Soluble R-SiO ${ }_{1.5} / \mathrm{TiO}_{2}$ Hybrid Nanoparticles by Cocondensation}

Titania-silica mixed oxides have attracted significant research interest, because of their wide range of applications, such as glasses with a low thermal coefficient [36] or high strength [37], super-hydrophilic surfaces [38, 39], implant coatings for direct tissue attachment $[40,41]$, high- $k$ dielectric materials [42], optical sensors [43-45], antireflection coating for solar cells [46], optical planar waveguide [47-49], and heterogeneous catalysts [50-54]. Various kinds of $\mathrm{TiO}_{2}-\mathrm{SiO}_{2}$ composites have been developed, which involve spherical particles $[55,56]$, thin films $[39,44,46]$, fibers $[57,58]$, and porous materials $[50,54,59]$. Manipulation of the size, shape, microstructures, and surface area is crucial to improve characteristic properties, such as catalytic activity, photoactivity, chemical durability, and optical and thermal properties.

Novel water-soluble $\mathrm{R}-\mathrm{SiO}_{1.5} / \mathrm{TiO}_{2}$ hybrid nanoparticles were synthesized by hydrolytic cocondensation of titanium alkoxides $\left(\mathrm{Ti}\left(\mathrm{OR}^{\prime}\right)_{4} \mathrm{R}^{\prime}=\right.$ ethyl, isopropyl, and butyl) with the hydroxyl-functionalized triethoxysilane precursor (Figure 2(e)) [60]. Cocondensation of a titanium alkoxide with the triethoxysilane precursor was investigated at different feed ratios, suggesting that water-soluble nanoparticles were obtained only at less than $30 \%$ of $\mathrm{Ti}(\mathrm{OEt})_{4}$ molar ratio in the feed. In contrast, the cocondensation of titanium tetraisopropoxide, $\mathrm{Ti}\left(\mathrm{O}^{\mathrm{i}} \mathrm{Pr}\right)_{4}$, with the triethoxysilane precursor in the presence of acetylacetone proceeded as a homogeneous system until $70 \%$ of $\operatorname{Ti}\left(\mathrm{O}^{\mathrm{i}} \mathrm{Pr}\right)_{4}$ molar ratio to afford water-soluble organic-inorganic hybrid nanoparticles containing titania-silica mixed oxides (Figure 6(b)), as confirmed by NMR, FT-IR, elemental, and ICP analyses. SFM measurements of the product prepared at $\mathrm{Ti}\left(\mathrm{O}^{\mathrm{i}} \mathrm{Pr}\right)_{4} /$ the triethoxysilane $=50 / 50 \mathrm{~mol} \%$ with acetylacetone indicated the formation of the nanoparticles having relatively narrow size distribution with average particle diameter less than $2.0 \mathrm{~nm}$ without aggregation. The refractive index of the hybrid nanoparticle was 1.571 . The isolated nanoparticles distributed homogeneously were visualized by TEM, and the size of the hybrid nanoparticle $(1.9 \mathrm{~nm})$ was determined by XRD.

\section{Cationic Hybrid Nanoparticles}

Cationic silsesquioxane-based materials with tunable properties and well-defined multidimensional architectures have become of special interest, because of their industrial importance and scientifically interesting properties. The potential applications involve biocompatible drug carrier [61], detection of conformation transformation of doublestranded DNA [62], probe for the detection of DNA [63], light-harvesting unimolecular nanoparticle for fluorescence amplification in cellular imaging [64], modification of montmorillonite [65], and preparation of nanocomposite thin 


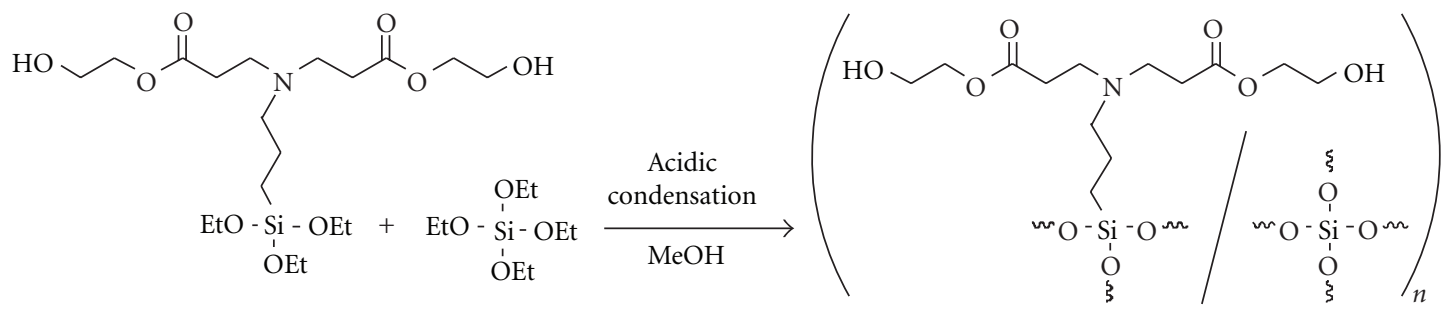

(a) Cocondensation of $\mathrm{Si}(\mathrm{OEt})_{4}$ with the triethoxysilane precursor<smiles>C=CCC(C)=O</smiles>

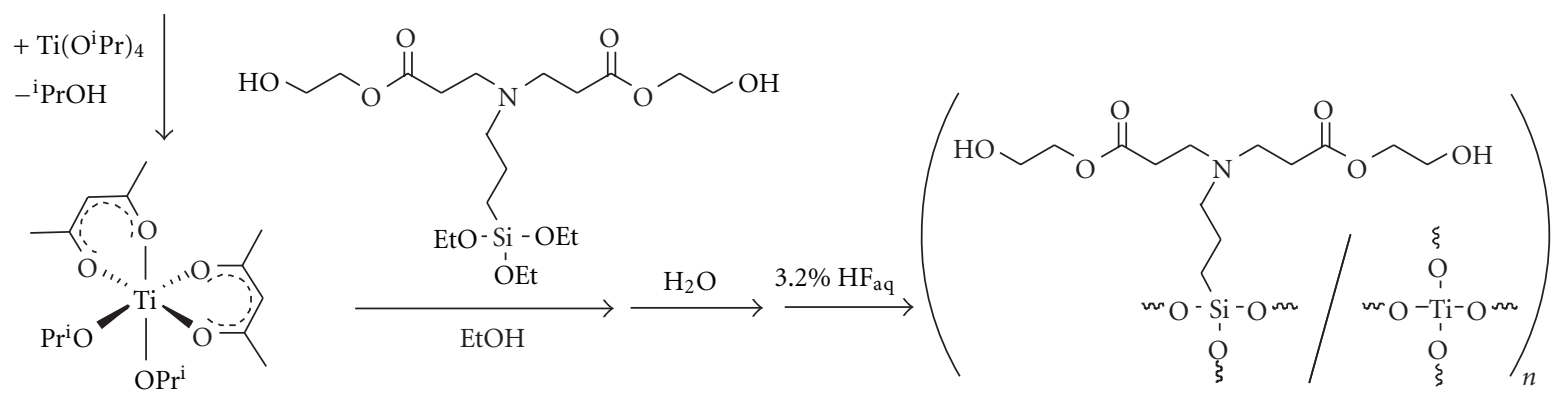

(b) Cocondensation of $\mathrm{Ti}\left(\mathrm{O}^{\mathrm{i}} \mathrm{Pr}\right)_{4}$ with the triethoxysilane in the presence of acetylacetone

FIGURE 6: Synthesis of hybrid nanoparticles by cocondensation of the hydroxyl-functionalized triethoxysilane precursor derived from 2-hydroxyethyl acrylate (HEA).

films via layer-by-layer electrostatic self-assembly $[22,66]$. Most of these cationic silsesquioxanes have been prepared from octafunctional polyhedral oligomeric silsesquioxanes, consisting of a rigid, crystalline silica-like core that is perfectly defined spatially $(0.5-0.7 \mathrm{~nm})$ and that can be linked covalently to eight $\mathrm{R}$ groups, such as octavinyl- and octaamino-substituted ones.

Recently, the synthesis of novel cationic silsesquioxane hybrids having uniform size distribution and characteristic water-soluble property by hydrolytic condensation of a triethoxysilane precursor derived from 2-(dimethylamino)ethyl acrylate (DMAEA) was reported, as shown in Figure 2(c) [67]. The development of an easily accessible mixture of silsesquioxanes with ionic or ionizable groups is one option for their exploitation in practical applications. As shown in Figure 7(a), the first step is the addition reaction of aminopropyltriethoxysilane and DMAEA, followed by hydrolytic condensation of the addition product to afford silsesquioxane hybrid. Acidic condensation of the DMAEAbased triethoxysilane precursor proceeded as a homogeneous system in methanol at room temperature to afford the water-soluble hybrid almost quantitatively. In addition to the ester groups, the resulting silsesquioxane hybrid exhibits a high density of chemically bonded peripheral tertiary amino groups on the outermost surface, which leads to watersolubility and various characteristic properties. The relatively low polydispersity $\left(M_{w} / M_{n}=1.33\right)$ and a reasonable molecular weight $\left(M_{n}=2700\right)$ were confirmed by SEC measurement. The size of the silsesquioxane hybrid $(1.7 \mathrm{~nm})$ was also determined by XRD. Quaternization reaction of the tertiary amine-containing hybrids with methyl iodide led to cationic silsesquioxane hybrids containing quaternized amine functionalities, which showed good solubility in polar solvents. SFM measurements indicated the formation of the cationic silsesquioxane hybrids having relatively narrow size distribution with average particle diameter (about $2.0 \mathrm{~nm}$ ) without aggregation. Hence, it is entirely fair to say that the product obtained by the hydrolytic condensation of the functional precursor derived from DMAEA is a mixture of silsesquioxanes having different silicon atoms, which can be called silsesquioxane-based nanoparticles, because their structures are topologically equivalent to a sphere. Note that polyhedral silsesquioxanes are often referred to as spherosiloxanes, since polyhedral structures are topologically equivalent to a sphere. Cocondensation of TEOS with the triethoxysilane precursor was carried out under different feed ratios, and water-soluble products were obtained in the cases of TEOS molar ratio up to $40 \%$ (Figure 7(b)). This convenient synthetic approach may lead to further development of novel organic-inorganic hybrids, because of the characteristic properties of the cationic silsesquioxane hybrid, such as high functionalities, solubility in aqueous medium, nanometer size, and narrow size distribution. 


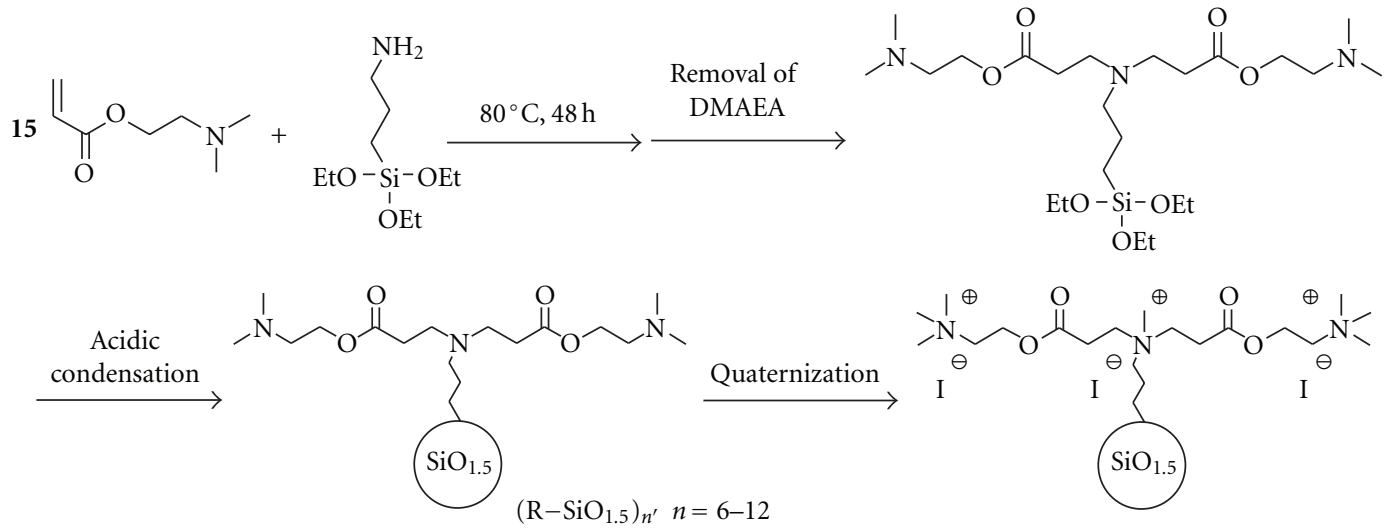

(a)<smiles>CCO[Si](CC)(OCC)OCC</smiles><smiles>CO[Si](O)(OC)O[Si](CCCN(CCC(=O)OCCN(C)C)CCC(=O)OCCN(C)C)(OC)OC</smiles>

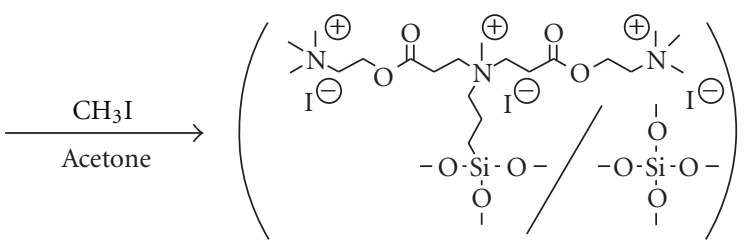

(b)

FIGURE 7: Synthetic routes for cationic silsesquioxane hybrids by (a) hydrolytic condensation of a functionalized precursor derived from 2(dimethylamino)ethyl acrylate (DMAEA), followed by quaternization, and (b) hydrolytic cocondensation of tetraethoxysilane (TEOS) with the DMAEA-based triethoxysilane precursor.

\section{Fluorinated Silsesquioxane-Based Hybrids}

In recent years, increasing attention has been paid to fluorinated silsesquioxanes, which consist of a siliconoxygen core framework and a fluoroalkyl shell. For example, fluorinated polyhedral oligomeric silsesquioxane molecules, in which the rigid cage is surrounded by perfluoroalkyl groups, were employed in the design of superoleophobic surfaces [68]. In this system, the fluorinated silsesquioxanes exhibited limited solubility because they were synthesized by basic condensation of triethoxysilane derivatives having hydrophobic and oleophobic fluoroalkyl groups such as $1 \mathrm{H}, 1 \mathrm{H}, 2 \mathrm{H}, 2 \mathrm{H}$-heptadecafluorodecyl and $1 \mathrm{H}, 1 \mathrm{H}, 2 \mathrm{H}, 2 \mathrm{H}$ tridecafluorooctyl groups $[68,69]$. A number of fluorinated polyhedral oligomeric silsesquioxane structures possessing a high degree of hydrophobicity has been prepared via a facile corner-capping methodology using various fluoroalkyl trichlorosilanes [70, 71]. A fluorinated polyhedral oligomeric silsesquioxane was also prepared by hydrosilylation of octakis(dimethylsiloxy)silsesquioxane with a fluorinated allyl ether derivative [72]. Another example is the synthesis of a heteroleptic silsesquioxane consisting of perfluoro, isooctyl, and amino (or alkoxy) groups by basic hydrolysis of the corresponding trialkoxysilane precursors $[73,74]$. Fluorinated silsesquioxane/polymer hybrids have recently inspired additional research efforts in which the silsesquioxane component has been either blended or covalently linked with a polymer [75-79]. Various fluorinated silsesquioxane/polymer hybrids have been also employed for modification of surface dewettability [80-82] and in lithography $[83,84]$.

Recently, the synthesis of novel low-refractive-index fluorinated silsesquioxane-based hybrids that have uniform size distribution, good solubility, and a tunable refractive index by hydrolytic condensation of triethoxysilane precursors derived from fluoroalkyl acrylates was demonstrated (Figure 3(a)) [85]. As shown in Figure 8(a), the first step is the addition reaction of aminopropyltriethoxysilane and fluoroalkyl acrylates, followed by acidic condensation of the addition products. Two acrylates having different fluoroalkyl chains- $1 H, 1 H, 5 H$-octafluoropentyl acrylate (OFPA) and 2,2,2-trifluoroethyl acrylate (TFEA) — were employed for the preparation of the fluorinated triethoxysilane precursors $\left(\mathrm{R}-\mathrm{Si}\left(\mathrm{OCH}_{2} \mathrm{CH}_{3}\right)_{3}\right)$. The condensation of the fluorinated triethoxysilane precursors in the presence of a small amount of HF aqueous solution proceeded as a homogeneous system 


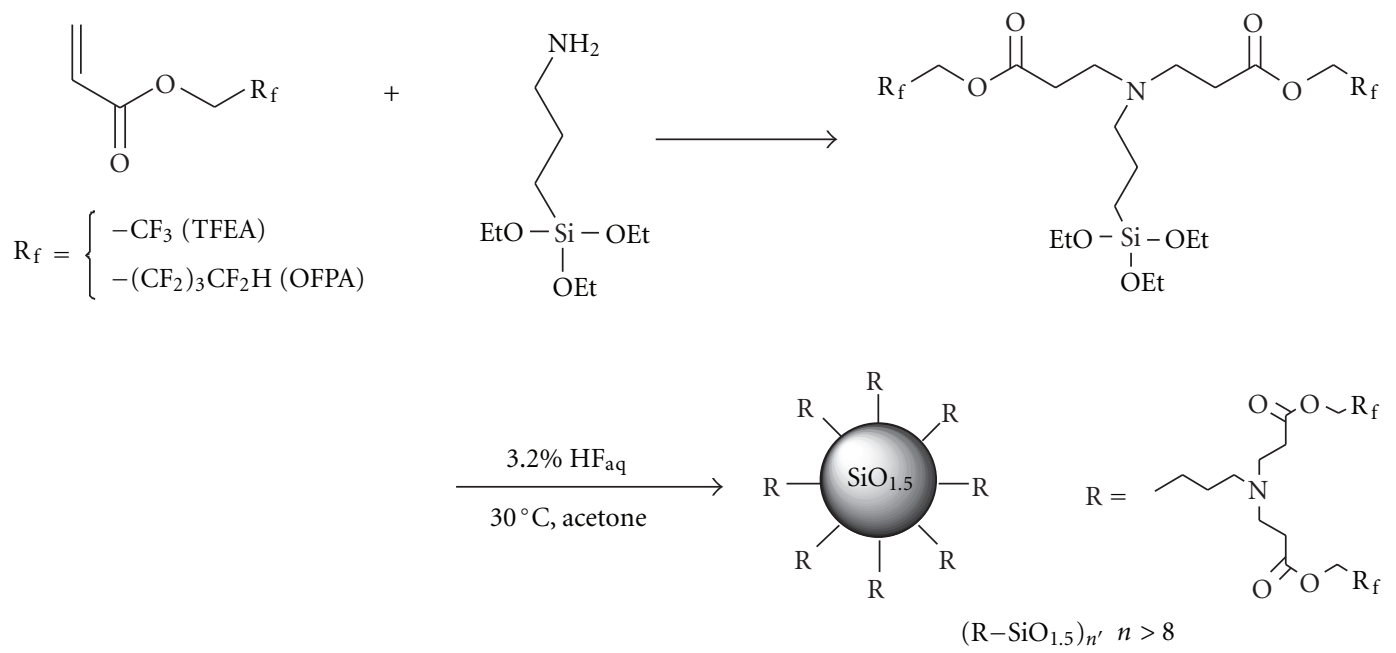

(a)<smiles>CCOC(=O)CCN(CCC[Si](OCC)(OCC)OCC)CCC(=O)OCC(F)(F)F</smiles><smiles>CCCCC(C)(C)C(C)(C)C(C)(C)OC(=O)CCN(CCCC(=O)OCC(C)(C)C)CCC[Si](OCC)(OCC)OCC</smiles>

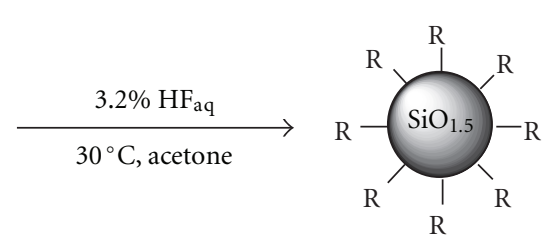

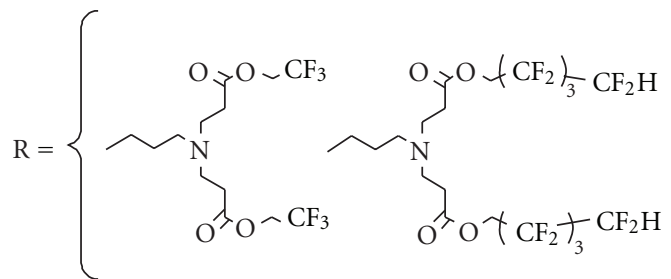

(b)

FIGURE 8: Synthetic routes for fluorinated silsesquioxane-based hybrids obtained via (a) hydrolytic condensation of triethoxysilane precursors derived from fluoroalkyl acrylates, and (b) hydrolytic cocondensation of TFEA-based and OFPA-based triethoxysilane precursors.

in acetone at $30^{\circ} \mathrm{C}$ until the end of the reaction. After the solvents (acetone and ethanol) were evaporated in a vacuum, the products were obtained quantitatively. The products were soluble in a variety of organic solvents, including $\mathrm{CHCl}_{3}$, THF, and acetone, but were insoluble in hexane and water. The resulting silsesquioxane-based hybrids exhibited a high density of chemically bonded peripheral fluoroalkyl groups, which led to various characteristic properties, including a low refractive index. The low polydispersities and reasonable molecular weights of the resulting fluorinated silsesquioxanes $\left(M_{n}=4800, M_{w} / M_{n}=\right.$ 1.01; and $M_{n}=4300, M_{w} / M_{n}=1.07$ for the OFPA- and TFEA-based products, resp.) were confirmed by SEC. The formation of spherical hybrids having relatively narrow size distributions (average particle diameter $<3.0 \mathrm{~nm}$ ) without aggregation was confirmed by SFM measurements. The XRD and DSC measurements indicated that the fluorinated silsesquioxane hybrids can be regarded as amorphous glass having low glass transition temperatures. Different from the cubic silsesquioxane crystals, some silsesquioxanes having long and/or specific substituent groups were amorphous, which showed broad XRD peaks [86-88]. Similar to such amorphous silsesquioxanes, the fluorinated silsesquioxane hybrids [85], hydroxyl-functionalized silsesquioxane hybrids [35], and cationic silsesquioxane hybrids [67] synthesized via the one-step condensation of the bulky triethoxysilane precursors can be regarded as amorphous glasses, which are mainly due to the long alkyl groups. The refractive indexes of the TFEA- and OFPA-based silsesquioxane hybrids were 1.43 and 1.40 , respectively.

Cocondensation of the TFEA- and OFPA-based triethoxysilane precursors afforded a series of fluorinated hybrids whose refractive index and various other properties can be manipulated by varying the composition of the feed (Figure 8(b)). The formation of hybrids having spherical structures via hydrolytic cocondensation was also confirmed 


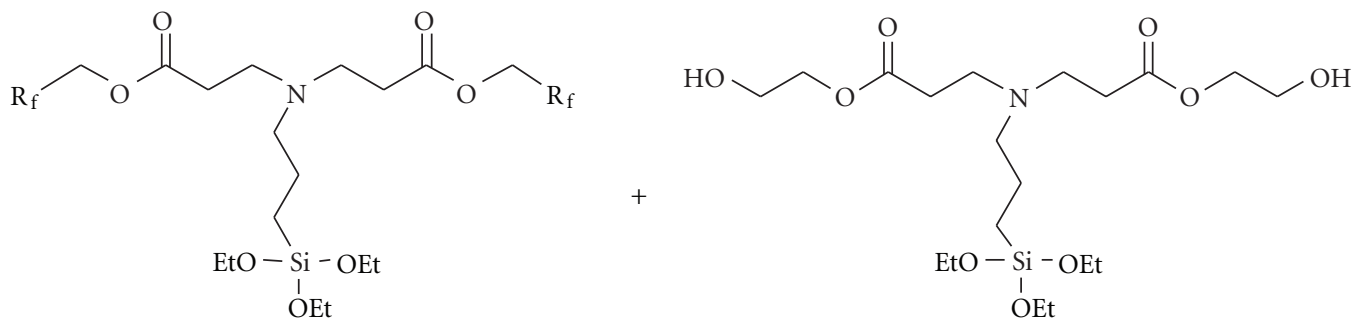

$\mathrm{R}_{\mathrm{f}}=-\mathrm{CF}_{3}$ (TFEA-based triethoxysilane)

$-\left(\mathrm{CF}_{2}\right)_{3} \mathrm{CF}_{2} \mathrm{H}$ (OFPA-based triethoxysilane)

HEA-based triethoxysilane
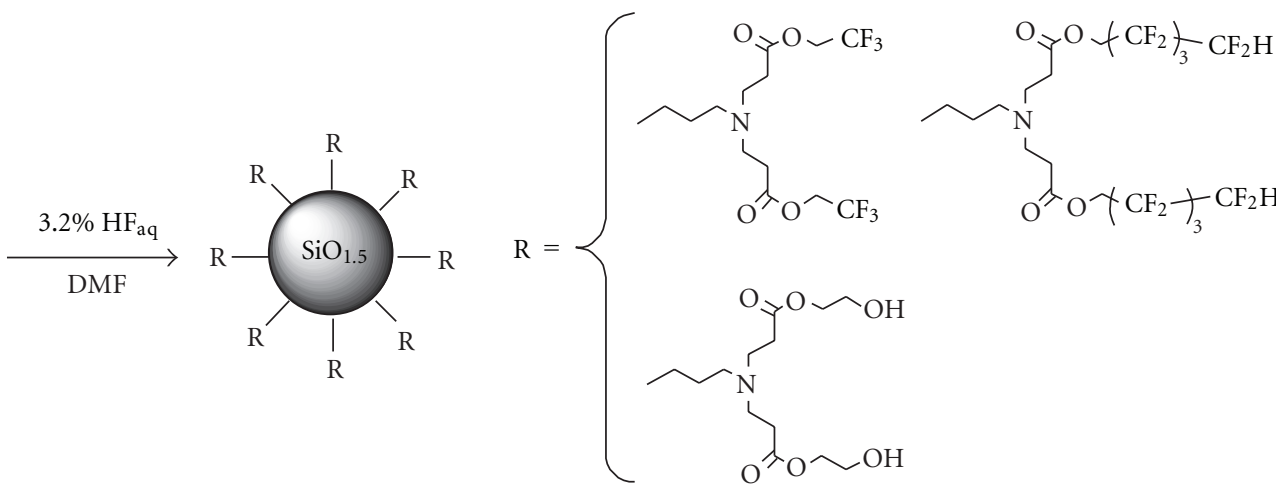

Figure 9: Synthetic route for the amphiphilic silsesquioxane-based hybrids based on hydrolytic cocondensation of the hydroxylfunctionalized triethoxysilane precursor and fluorinated triethoxysilane precursors.

by XRD and SFM measurements. Low refractive indexes of the fluorinated silsesquioxane-based hybrids could be tuned by adjusting the feed ratio of the TFEA-based and OFPAbased triethoxysilane precursors in the cocondensation (Figure 3(b)).

\section{Amphiphilic Silsesquioxane-Based Hybrids}

Silsesquioxanes having two or more different organic groups immobilized to an inorganic core have recently attracted considerable attention, because of their intriguing phase behavior and enormous potential as a building block for various advanced materials [5]. For example, Gunawidjaja et al. reported bulk and surface assembly of amphiphilic silsesquioxane compounds with various hydrophilic and hydrophobic terminal group compositions [28]. For the synthesis of silsesquioxanes having different substituent groups, several methods have been employed, which involve cohydrolysis/cocondensation of chlorosilanes and alkoxysilanes, corner-capping method, and synthetic modification of a preexisting silsesquioxane compound [5]. During recent years, there has been increasing attention paid to silsesquioxanes having fluoroalkyl chain as a hydrophobic component and another organic group. The synthesis of heteroleptic silsesquioxane consisting of perfluoro, isooctyl, and amino (or alkoxy) groups was conducted by basic hydrolysis of corresponding trialkoxysilane precursors [73, 74]. A number of fluorinated polyhedral oligomeric silsesquioxanes structures possessing another organic group has been prepared via a facile corner-capping methodology [70, 71]. Additionally, fluorinated polyhedral oligomeric silsesquioxanes possessing one reactive functional group by the cornercapping method were employed for preparation of various fluorinated silsesquioxanes/polymer hybrids [89-91].

Amphiphilic silsesquioxanes-based hybrids were synthesized by hydrolytic cocondensation of a hydroxylfunctionalized triethoxysilane precursor derived from 2hydroxyethyl acrylate (HEA) and fluorinated triethoxysilane precursors derived from $1 \mathrm{H}, 1 \mathrm{H}, 5 \mathrm{H}$-octafluoropentyl acrylate (OFPA) and 2,2,2-trifluoroethyl acrylate (TFEA), as shown in Figure 9 [92]. The OFPA-based triethoxysilane precursor has a bulky fluoroalkyl group attached to a silicon atom, whereas the TFEA-based precursor has a shorter fluoroalkyl group. The bulkiness of the fluoroalkyl group may have some influence on the internal cyclization, resulting in the formation of closed structures and avoidance of gelation. On the basis of the preparation method (hydrolytic cocondensation of two different triethoxysilanes, $\mathrm{R}_{\mathrm{f}}-\mathrm{Si}(\mathrm{OEt})_{3}$ and $\left.\mathrm{R}_{\mathrm{OH}}-\mathrm{Si}(\mathrm{OEt})_{3}\right)$, the general structure of the hybrids is expected to be $\left(\left[\mathrm{R}_{\mathrm{f}}-\mathrm{co}-\mathrm{R}_{\mathrm{OH}}\right]-\mathrm{SiO}_{1.5}\right)_{n}$, where each silicon atom is bound to an average of one-and-a-half oxygens and to one alkyl chain involving the fluoroalkyl groups or hydroxyalkyl groups. The resulting amphiphilic silsesquioxane hybrids should have fluoroalkyl groups and hydroxyalkyl groups on the outermost surface, in addition to the tertiary amino groups and ester groups, which lead to various characteristic properties. 

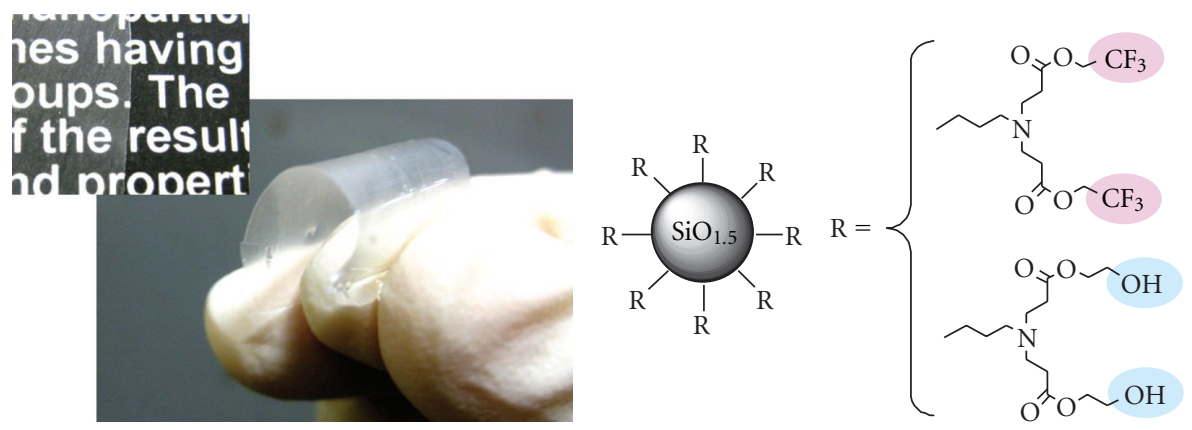

Figure 10: Photograph of flexible film of the TFEA-co-HEA silsesquioxane hybrid prepared by hydrolytic cocondensations. Reprinted with permission from [92]. Copyright 2012 Elsevier.

Hydrolytic cocondensations of two functionalized triethoxysilane precursors proceeded as homogeneous systems in $N, N$-dimethylformamide (DMF) to afford amphiphilic silsesquioxanes hybrids, which were soluble in a variety of solvents, depending on the composition. The structure of the constitutional unit of the hybrids was confirmed by the results of NMR and FT-IR measurements. SFM and XRD measurements indicated the formation of spherical hybrids having relatively narrow size distributions (average particle diameter $<3.0 \mathrm{~nm}$ ) without aggregation. Cocondensation of the hydroxyl-functionalized precursor (HEA-based triethoxysilane) and fluorinated precursors (OFPA-based and TFEA-based triethoxysilane) provided amphiphilic hybrid materials, in which solubility, amphiphilicity, refractive index, film forming, and various properties could be manipulated by the composition in the feed (Figure 3(c)). As can be seen in Figure 10, flexible semitransparent films were obtained from the amphiphilic silsesquioxane hybrids having hydrophilic and hydrophobic chains connected chemically to an inorganic core, which were prepared by hydrolytic cocondensations at suitable feed ratios [92]. Note that self-standing hybrid films were obtained from the amphiphilic silsesquioxane hybrids in this system without any addition of cross-linker and polymer, although most of film-forming nanocomposites were prepared from organicinorganic hybrid systems comprising of polymer chains and inorganic particles. In the systems, the formation of the flexible semitransparent films would be the result of specific interactions between the hydroxyl groups, tertiary amino groups, fluoroalkyl groups, and ester groups in the amphiphilic silsesquioxane hybrids. The presence of intermolecular interactions between these functional groups of the hybrids may contribute to achieving good filmforming property, in which physically cross-linked polymerlike materials can be easily fabricated into the self-standing hybrid films.

\section{Stimuli-Responsive Organic-Inorganic Hybrids}

Stimuli-responsive organic-inorganic hybrids have recently attracted considerable interest, because combination with inorganic materials offers the opportunity to develop new nanosized "intelligent" or "smart" hybrids [25, 93-97]. Manipulation of specific intermolecular interactions, such as hydrogen-bonding, acid-base interactions, and oppositely charged ionic interactions, is crucial for the design and development of stimuli-responsive organic-inorganic hybrid structures with nanometer dimensions [98-101]. The water soluble silsesquioxane-based nanoparticles obtained from glycidol (Figure 4(a)) could be used as a component for characteristic intelligent colloidal hybrids, in which the complexation of tertiary amine-containing nanoparticles and a weak anionic polyelectrolyte can be manipulated simply by $\mathrm{pH}$ change in aqueous solution (Figure 2(f)) $[25,97]$. Poly(acrylic acid), PAA, was selected as a weak polyelectrolyte, because the degree of ionization of carboxylic acids can be easily controlled by the $\mathrm{pH}$ value. In this system, both PAA and the silsesquioxane nanoparticles formed visually transparent solutions in water, while a white turbid dispersion was obtained just after mixing the two solutions at room temperature. The complex formation in water was strongly affected by the $\mathrm{pH}$ value, and the $\mathrm{pH}$-induced association-dissociation behavior was a reversible and rapid process. The reversible $\mathrm{pH}$-induced colloid formation due to the complexation of the inorganic-organic nanomaterials can provide a viable route to the production of tailored materials with unique properties for various applications.

The nature of the interaction of biomolecules, such as proteins, peptides, and amino acids, with inorganic materials is a subject of extraordinary relevance due to increasing interest in biointerfaces for medical, diagnostic, and biotechnology applications. In recent years, increasing attention has also been paid to developing silsesquioxane/biomolecule hybrids [102-109]. A series of researches in the design and synthesis of amino acid-based polymers including stimuliresponsive polymers, such as $\mathrm{pH}$-responsive, thermoresponsive, and dual-stimuli-responsive block copolymers, and self-assembled block copolymers having tunable chiroptical properties, have been reported, which were obtained by reversible addition-fragmentation chain transfer (RAFT) polymerization [110].

Recently, smart amino acid-based polymer/silsesquioxane hybrids was developed, in which the complexation of water-soluble silsesquioxane nanoparticles [35], derived from HEA-based triethoxysilane (Figure 11(a)), and amino 
$\mathrm{pH}<2$

$\mathrm{pH}>10$

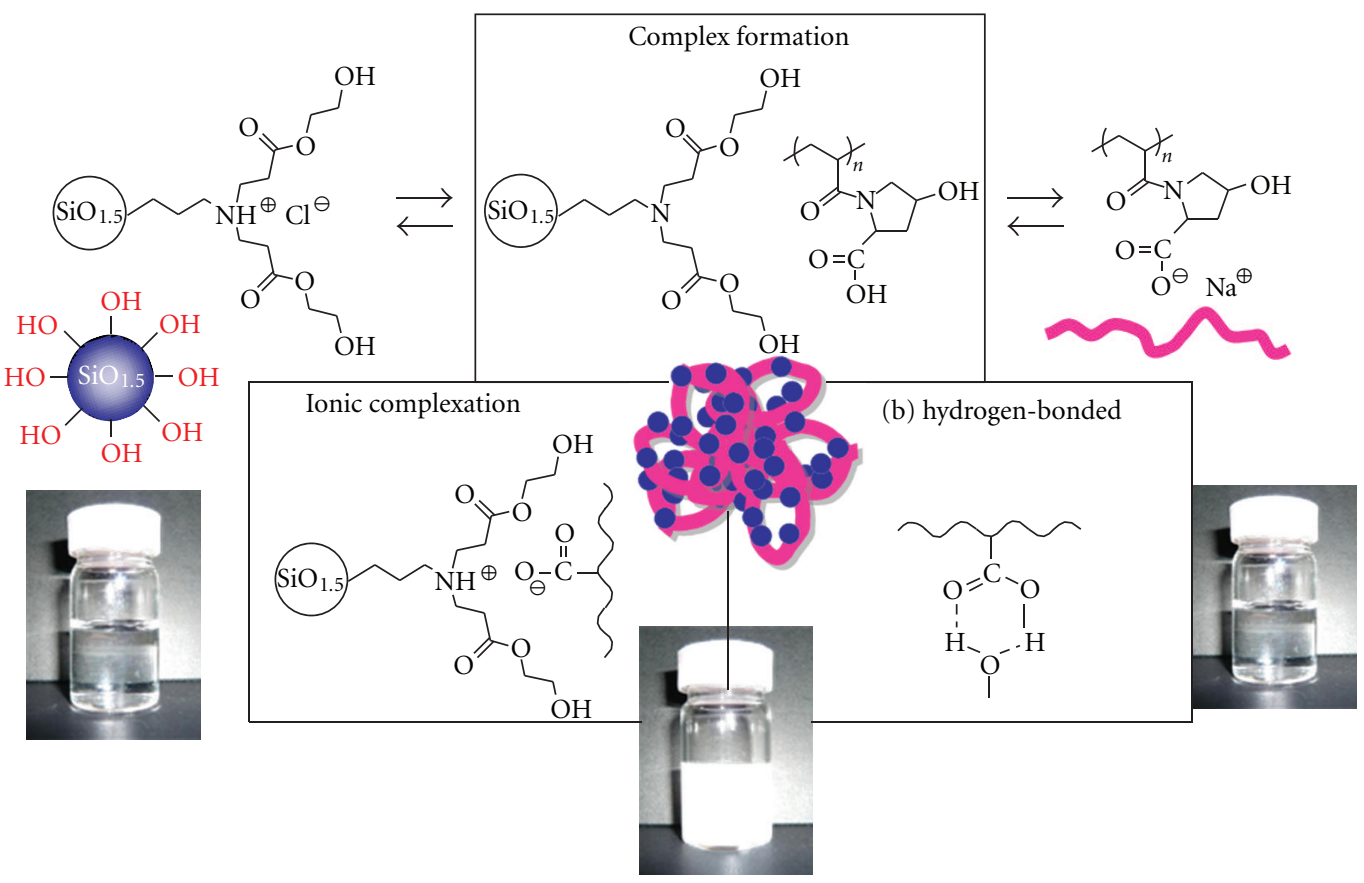

(a)

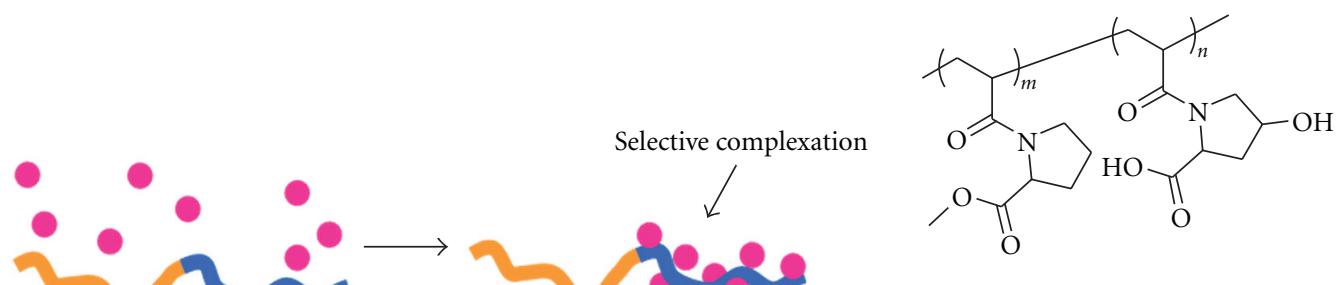

Poly(A-Pro-OMe)-b-Poly(A-Hyp-OH)

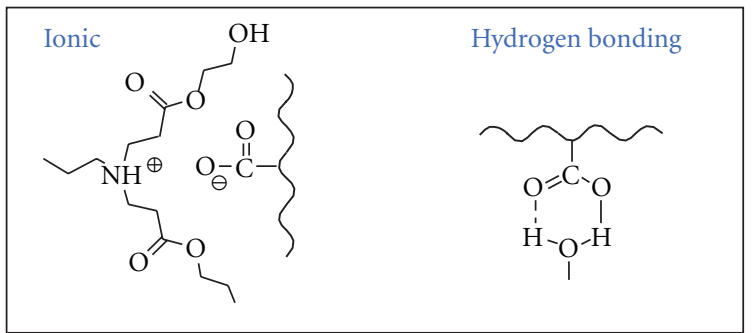<smiles>CCC(C)C(C)C(=O)N1CCCC1C(=O)OC</smiles>

Poly(A-Pro-OMe)-b-Poly(A-Hyp-OMe)

(b)

FIgURE 11: Smart organic-inorganic hybrids based on (a) complexation of amino acid-based polymer and water-soluble silsesquioxane nanoparticles, and (b) selective complexation of the silsesquioxane nanoparticles and block copolymer.

acid-based polymer, can be manipulated by $\mathrm{pH}$ changes in aqueous media [111]. The nanoparticles obtained from HEA-based triethoxysilane should have many ester groups on the surface, which may contribute hydrogen bond and therefore affect stimuli-responsive complexation of tertiary amine-containing nanoparticles and a weak anionic polyelectrolyte. Simple mixing of aqueous solutions of the amino acid-based polymer obtained from $\mathrm{N}$-acryloyl-4-transhydroxy-l-proline (A-Hyp-OH) [112] and the silsesquioxane nanoparticles led to the straightforward formation of the
pH-responsive hybrids, in which a white turbid dispersion was observed at $\mathrm{pH}=5-8$, whereas transparent solutions were obtained at $\mathrm{pH}=2$ and 10 (Figure 11(a)). The methylated sample, poly(A-Hyp-OMe), exhibited a characteristic soluble-insoluble transition at around $49.5^{\circ} \mathrm{C}$ [112], and thermoresponsive hybrids were obtained by complexation of the silsesquioxane nanoparticles with poly(A-Hyp-OMe) [111]. In contrast, poly( $N$-acryloyl-l-proline methyl ester) and poly(A-Pro-OMe), exhibited a relatively lower phaseseparation temperature (around $18^{\circ} \mathrm{C}$ ) in neutral water 
$(\mathrm{pH}=7)$ [113-115], and the thermoresponsive polymer showed no specific interaction with the silsesquioxane nanoparticles [111].

Self-assembly of block copolymer/nanoparticle hybrids has also generated significant research interest, because the nanoparticles can be spatially organized in the formed aggregates [29, 116-120]. Depending on the chemical nature of the functional segments and their composition, the block copolymers afford a great opportunity for tuning chemical and physical properties as well as assembled structures. Additionally, the size, shape, and nature of the inorganic nanoparticles and specific interactions between the organic and inorganic components act as crucial elements to provide an effective route for the controlled self-ordering of nanoparticles with polymers and for the endowment of characteristic properties. Smart organic-inorganic hybrids were prepared using noncovalent interactions between watersoluble silsesquioxane nanoparticles containing tertiary amine moieties and two amino acid-based block copolymers prepared by RAFT polymerization (Figure 11(b)) [121]. A dual thermoresponsive block copolymer displaying LCST and UCST was employed, in which only the poly(AHyp-OH) segment could interact with the silsesquioxane nanoparticles, whereas another poly(A-Pro-OMe) segment showed a characteristic thermoresponsive property without any interaction with the nanoparticles. The simple mixing procedure of two transparent aqueous solutions led to the formation of smart organic-inorganic hybrids through the selective complexation of the silsesquioxane nanoparticles and the poly $(\mathrm{A}-\mathrm{Hyp}-\mathrm{OH})$ segment in the block copolymer.

\section{Conclusion}

This paper has summarized recent development of the silsesquioxanes-based nanoparticles prepared by hydrolytic condensation of bulky triethoxysilane precursors derived from functional acrylate derivatives. The addition reaction of aminopropyltriethoxysilane with 2-hydroxyethyl acrylate (HEA), 2-(dimethylamino)ethyl acrylate (DMAEA), $1 \mathrm{H}, 1 \mathrm{H}, 5 \mathrm{H}$-octafluoropentyl acrylate (OFPA), and 2,2,2trifluoroethyl acrylate (TFEA) afforded functional triethoxysilane precursors. The hydrolytic condensation of the addition products proceeded as homogeneous systems under suitable conditions to afford the functional silsesquioxane hybrids almost quantitatively. The development of an easily accessible mixture of silsesquioxanes with a variety of functional groups is one option for their exploitation in practical applications. This convenient synthetic approach have allowed great advances in the further development of novel organic-inorganic hybrids, because of the characteristic properties of the functional silsesquioxane hybrid, such as high functionalities, solubility in aqueous medium, nanometer size, and narrow size distribution. Depending on the chemical nature of the functional trietoxysilane precursors, additional component (trialkoxysilanes and metal alkoxides used for the cocondensation), and their composition, the silsesquioxane hybrids afforded great flexibility for tuning functional groups in the organic part, components of the inorganic parts, and various properties as well as size and shape of the hybrids. The manipulation of noncovalent interactions such as hydrogen bonding and interelectrolyte interaction was also crucial for providing organic-inorganic smart hybrids having characteristic stimuli-responsive properties. The multiscale ordering of such functional nanomaterials is a powerful technique for the creation of tailored hybrid materials with unique properties for various applications.

\section{Acknowledgments}

The author acknowledges Professor Takeshi Endo (Director of Molecular Engineering Institute, Kinki University and Vice President of Kinki University) and Professor Koichiro Yonetake (Yamagata University) for helpful suggestions, discussions, and collaborations.

\section{References}

[1] P. Eisenberg, R. Erra-Balsells, Y. Ishikawa et al., "Cagelike precursors of high-molar-mass silsesquioxanes formed by the hydrolytic condensation of trialkoxysilanes," Macromolecules, vol. 33, no. 6, pp. 1940-1947, 2000.

[2] F. J. Feher and T. A. Budzichowski, "Silasesquioxanes as ligands in inorganic and organometallic chemistry," Polyhedron, vol. 14, no. 22, pp. 3239-3253, 1995.

[3] M. G. Voronkov and V. I. Lavrent'yev, "Polyhedral oligosilsesquioxanes and their homo derivatives," Topics in Current Chemistry, vol. 102, pp. 199-236, 1982.

[4] P. P. Pescarmona and T. Maschmeyer, "Oligomeric silsesquioxanes: synthesis, characterization and selected applications," Australian Journal of Chemistry, vol. 54, no. 9-10, pp. 583-596, 2001.

[5] D. B. Cordes, P. D. Lickiss, and F. Rataboul, "Recent developments in the chemistry of cubic polyhedral oligosilsesquioxanes," Chemical Reviews, vol. 110, no. 4, pp. 2081-2173, 2010.

[6] S. Sulaiman, A. Bhaskar, J. Zhang, R. Guda, T. Goodson III, and R. M. Laine, "Molecules with perfect cubic symmetry as nanobuilding blocks for 3-D assemblies. Elaboration of octavinylsilsesquioxane. Unusual luminescence shifts may indicate extended conjugation involving the silsesquioxane core," Chemistry of Materials, vol. 20, no. 17, pp. 5563-5573, 2008.

[7] R. Y. Kannan, H. J. Salacinski, P. E. Butler, and A. M. Seifalian, "Polyhedral oligomeric silsesquioxane nanocomposites: the next generation material for biomedical applications," Accounts of Chemical Research, vol. 38, no. 11, pp. 879-884, 2005.

[8] R. M. Laine, "Nanobuilding blocks based on the $\left[\mathrm{OSiO}_{1.5}\right]_{x}$ ( $x=6,8,10)$ octasilsesquioxanes," Journal of Materials Chemistry, vol. 15, no. 35-36, pp. 3725-3744, 2005.

[9] P. D. Lickiss and F. Rataboul, "Chapter 1 fully condensed polyhedral oligosilsesquioxanes (POSS): from synthesis to application," Advances in Organometallic Chemistry, vol. 57, pp. 1-116, 2008.

[10] A. Provatas and J. G. Matisons, "Silsesquioxanes: synthesis and applications," Trends in Polymer Science, vol. 5, pp. 327332, 1997.

[11] C. Zhang and R. M. Laine, "Hydrosilylation of allyl alcohol with $\left[\mathrm{HSiMe}_{2} \mathrm{OSiO}_{1.5}\right]_{8}$ : octa(3-hydroxypropyldimethylsiloxy)octasilsesquioxane and its octamethacrylate derivative as potential precursors to hybrid nanocomposites," 
Journal of the American Chemical Society, vol. 122, no. 29, pp. 6979-6988, 2000.

[12] P. A. Agaskar, V. W. Day, and W. G. Klemperer, "A new route to trimethylsilylated spherosilicates: synthesis and structure of $\left[\mathrm{Si}_{12} \mathrm{O}_{18}\right]\left(\mathrm{OSiMe}_{3}\right)_{12}, \mathrm{D}_{3 h^{-}}\left[\mathrm{Si}_{14} \mathrm{O}_{21}\right]\left(\mathrm{OSiMe}_{3}\right)_{14}$, and $\mathrm{C}_{2 v^{-}}$ $\left[\mathrm{Si}_{14} \mathrm{O}_{21}\right]\left(\mathrm{OSiMe}_{3}\right)_{14}$," Journal of the American Chemical Society, vol. 109, no. 18, pp. 5554-5556, 1987.

[13] C. L. Frye and W. T. Collins, "The oligomeric silsesquioxanes, $\left(\mathrm{HSiO}_{3 / 2}\right)_{n}$," Journal of the American Chemical Society, vol. 92, no. 19, pp. 5586-5588, 1970.

[14] R. J. J. Williams, R. Erra-Balsells, Y. Ishikawa, H. Nonami, A. N. Mauri, and C. C. Riccardi, "UV-MALDITOF and ESI-TOF mass spectrometry characterization of silsesquioxanes obtained by the hydrolytic condensation of (3-glycidoxypropyl)-trimethoxysilane in an epoxidized solvent," Macromolecular Chemistry and Physics, vol. 202, no. 11, pp. 2425-2433, 2001.

[15] L. M. Bronstein, C. N. Linton, R. Karlinsey et al., "Controlled synthesis of novel metalated poly(aminohexyl)(aminopropyl)silsesquioxane colloids," Langmuir, vol. 19, no. 17, pp. 7071-7083, 2003.

[16] C. Ma, I. Taniguchi, M. Miyamoto, and Y. Kimura, "Formation of stable nanoparticles of poly(phenyl/methylsilsesquioxane) in aqueous solution," Polymer Journal, vol. 35, no. 3, pp. 270-275, 2003.

[17] C. Ma and Y. Kimura, "Preparation of nano-particles of poly(phenylsilsesquioxane)s by emulsion polycondensation of phenylsilanetriol formed in aqueous solution," Polymer Journal, vol. 34, no. 9, pp. 709-713, 2002.

[18] N. Jungmann, M. Schmidt, and M. Maskos, "Characterization of polyorganosiloxane nanoparticles in aqueous dispersion by asymmetrical flow field-flow fractionation," Macromolecules, vol. 34, no. 23, pp. 8347-8353, 2001.

[19] P. Maitra and S. L. Wunder, "Oligomeric poly(ethylene oxide)-functionalized silsesquioxanes: interfacial effects on $\mathrm{Tg}, \mathrm{Tm}$, and $\delta \mathrm{Hm}$," Chemistry of Materials, vol. 14, no. 11, pp. 4494-4497, 2002.

[20] R. Knischka, F. Dietsche, R. Hanselmann, H. Frey, R. Mülhaupt, and P. J. Lutz, "Silsesquioxane-based amphiphiles," Langmuir, vol. 15, no. 14, pp. 4752-4756, 1999.

[21] K. Y. Mya, X. Li, L. Chen, X. Ni, J. Li, and C. He, "Core-corona structure of cubic silsesquioxane-poly(ethylene oxide) in aqueous solution: fluorescence, light scattering, and TEM studies," Journal of Physical Chemistry B, vol. 109, no. 19, pp. 9455-9462, 2005.

[22] G. Wu and Z. Su, "Polyhedral oligomeric silsesquioxane nanocomposite thin films via layer-by-layer electrostatic selfassembly," Chemistry of Materials, vol. 18, no. 16, pp. 37263732, 2006.

[23] B. L. Frankamp, N. O. Fischer, R. Hong, S. Srivastava, and V. M. Rotello, "Surface modification using cubic silsesquioxane ligands. facile synthesis of water-soluble metal oxide nanoparticles," Chemistry of Materials, vol. 18, no. 4, pp. 956959, 2006.

[24] H. Mori, M. G. Lanzendörfer, A. H. E. Müller, and J. E. Klee, "Silsesquioxane-based nanoparticles formed via hydrolytic condensation of organotriethoxysilane containing hydroxy groups," Macromolecules, vol. 37, no. 14, pp. 5228-5238, 2004.

[25] H. Mori, A. H. E. Müller, and J. E. Klee, "Intelligent colloidal hybrids via reversible $\mathrm{pH}$-induced complexation of polyelectrolyte and silica nanoparticles," Journal of the American Chemical Society, vol. 125, no. 13, pp. 3712-3713, 2003.
[26] S. Muthukrishnan, F. Plamper, H. Mori, and A. H. E. Müller, "Synthesis and characterization of glycomethacrylate hybrid stars from silsesquioxane nanoparticles," Macromolecules, vol. 38, no. 26, pp. 10631-10642, 2005.

[27] J. Xu and W. Shi, "Synthesis and crystallization kinetics of silsesquioxane-based hybrid star poly(elunate-caprolactone)," Polymer, vol. 47, no. 14, pp. 5161-5173, 2006.

[28] R. Gunawidjaja, F. Huang, M. Gumenna et al., "Bulk and surface assembly of branched amphiphilic polyhedral oligomer silsesquioxane compounds," Langmuir, vol. 25, no. 2, pp. 1196-1209, 2009.

[29] M. Schumacher, M. Ruppel, J. Yuan et al., "Smart organicinorganic nanohybrids based on amphiphilic block copolymer micelles and functional silsesquioxane nanoparticles," Langmuir, vol. 25, no. 6, pp. 3407-3417, 2009.

[30] V. N. Bliznyuk, T. A. Tereshchenko, M. A. Gumenna et al., "Structure of segmented poly(ether urethane)s containing amino and hydroxyl functionalized polyhedral oligomeric silsesquioxanes (POSS)," Polymer, vol. 49, no. 9, pp. 22982305, 2008.

[31] D. P. Fasce, R. J. J. Williams, F. Méchin, J. P. Pascault, M. F. Llauro, and R. Pétiaud, "Synthesis and characterization of polyhedral silsesquioxanes bearing bulky functionalized substituents," Macromolecules, vol. 32, no. 15, pp. 4757-4763, 1999.

[32] D. P. Fasce, R. J. J. Williams, R. Erra-Balsells, Y. Ishikawa, and H. Nonami, "One-step synthesis of polyhedral silsesquioxanes bearing bulky substituents: UV-MALDI-TOF and ESITOF mass spectrometry characterization of reaction products," Macromolecules, vol. 34, no. 11, pp. 3534-3539, 2001.

[33] I. E. dell'Erba, D. P. Fasce, R. J. J. Williams, R. Erra-Balsells, Y. Fukuyama, and H. Nonami, "Poly(silsesquioxanes) derived from the hydrolytic condensation of organotrialkoxysilanes containing hydroxyl groups," Journal of Organometallic Chemistry, vol. 686, no. 1-2, pp. 42-51, 2003.

[34] D. P. Fasce, I. E. Dell'Erba, and R. J. J. Williams, "Synthesis of a soluble functionalized-silica by the hydrolysis and condensation of organotrialkoxysilanes bearing ( $\beta$-hydroxy) tertiary amine groups with tetraethoxysilane," Polymer, vol. 46, no. 17, pp. 6649-6656, 2005.

[35] H. Mori, Y. Miyamura, and T. Endo, "Synthesis and characterization of water-soluble silsesquioxane-based nanoparticles by hydrolytic condensation of triethoxysilane derived from 2-hydroxyethyl acrylate," Langmuir, vol. 23, no. 17, pp. 9014-9023, 2007.

[36] Z. Deng, E. Breval, and C. G. Pantano, "Colloidal sol/gel processing of ultra-low expansion $\mathrm{TiO}_{2} / \mathrm{SiO}_{2}$ glasses," Journal of Non-Crystalline Solids, vol. 100, no. 1-3, pp. 364-370, 1988.

[37] S. Kirtay, E. Oktay, and V. Gunay, "Glass strengthening by $\mathrm{SiO}_{2}-\mathrm{TiO}_{2}$ organically modified silica coating," Thin Solid Films, vol. 515, no. 4, pp. 2145-2152, 2006.

[38] M. Houmard, D. Riassetto, F. Roussel et al., "Morphology and natural wettability properties of sol-gel derived $\mathrm{TiO}_{2}$ $\mathrm{SiO}_{2}$ composite thin films," Applied Surface Science, vol. 254, no. 5, pp. 1405-1414, 2007.

[39] S. Permpoon, M. Houmard, D. Riassetto et al., "Natural and persistent superhydrophilicity of $\mathrm{SiO}_{2} / \mathrm{TiO}_{2}$ and $\mathrm{TiO}_{2} / \mathrm{SiO}_{2}$ bi-layer films," Thin Solid Films, vol. 516, no. 6, pp. 957-966, 2008.

[40] V. Ääritalo, S. Areva, M. Jokinen, M. Lindén, and T. Peltola, "Sol-gel-derived $\mathrm{TiO}_{2}-\mathrm{SiO}_{2}$ implant coatings for direct tissue attachment. Part I: Design, preparation and 
characterization," Journal of Materials Science, vol. 18, no. 9, pp. 1863-1873, 2007.

[41] S. Areva, V. Ääritalo, S. Tuusa, M. Jokinen, M. Lindén, and T. Peltola, "Sol-Gel-derived $\mathrm{TiO}_{2}-\mathrm{SiO}_{2}$ implant coatings for direct tissue attachment. Part II: Evaluation of cell response," Journal of Materials Science, vol. 18, no. 8, pp. 1633-1642, 2007.

[42] D. K. Sarkar, D. Brassard, M. A. E. Khakani, and L. Ouellet, "Dielectric properties of sol-gel derived high-k titanium silicate thin films," Thin Solid Films, vol. 515, no. 11, pp. 4788-4793, 2007.

[43] M. Zaharescu, A. Barau, L. Predoana et al., " $\mathrm{TiO}_{2}-\mathrm{SiO}_{2}$ sol-gel hybrid films and their sensitivity to gaseous toluene," Journal of Non-Crystalline Solids, vol. 354, no. 2-9, pp. 693-699, 2008.

[44] A. Łukowiak, R. Dylewicz, S. Patela, W. Stręk, and K. Maruszewski, "Optical properties of $\mathrm{SiO}_{2}-\mathrm{TiO}_{2}$ thin film waveguides obtained by the sol-gel method and their applications for sensing purposes," Optical Materials, vol. 27, no. 9, pp. 1501-1505, 2005.

[45] X. Shu, Y. Chen, H. Yuan, S. Gao, and D. Xiao, " $\mathrm{H}_{2} \mathrm{O}_{2}$ sensor based on the room-temperature phosphorescence of nano $\mathrm{TiO}_{2} / \mathrm{SiO}_{2}$ composite," Analytical Chemistry, vol. 79, no. 10, pp. 3695-3702, 2007.

[46] S. Y. Lien, D. S. Wuu, W. C. Yeh, and J. C. Liu, "Tri-layer antireflection coatings $\left(\mathrm{SiO}_{2} / \mathrm{SiO}_{2}-\mathrm{TiO}_{2} / \mathrm{TiO}_{2}\right)$ for silicon solar cells using a sol-gel technique," Solar Energy Materials and Solar Cells, vol. 90, no. 16, pp. 2710-2719, 2006.

[47] W. Chen, X. Tao, J. Zhang, Q. Fang, and J. Yang, "Sol-gelprocessed $\mathrm{SiO}_{2} / \mathrm{TiO}_{2} /$ methylcellulose composite materials for optical waveguides," Journal of the American Ceramic Society, vol. 88, no. 11, pp. 2998-3002, 2005.

[48] N. D. Afify, R. Grisenti, G. Dalba et al., "Short-range order around $\mathrm{Er}^{3+}$ in silica waveguides containing aluminium, titanium and hafnium," Optical Materials, vol. 28, no. 6-7, pp. 864-867, 2006.

[49] A. C. Marques and R. M. Almeida, "Raman spectra and structure of multicomponent oxide planar waveguides prepared by sol-gel," Journal of Sol-Gel Science and Technology, vol. 40, no. 2-3, pp. 371-378, 2006.

[50] W. Dong, Y. Sun, C. W. Lee et al., "Controllable and repeatable synthesis of thermally stable anatase nanocrystalsilica composites with highly ordered hexagonal mesostructures," Journal of the American Chemical Society, vol. 129, no. 45, pp. 13894-13904, 2007.

[51] A. O. Bouh, G. L. Rice, and S. L. Scott, "Mono- and dinuclear silica-supported titanium(IV) complexes and the effect of TiOTi connectivity on reactivity," Journal of the American Chemical Society, vol. 121, no. 31, pp. 7201-7210, 1999.

[52] J. Jarupatrakorn and T. D. Tilley, "Silica-supported, singlesite titanium catalysts for olefin epoxidation. A molecular precursor strategy for control of catalyst structure," Journal of the American Chemical Society, vol. 124, no. 28, pp. 8380-8388, 2002.

[53] M. Fujiwara, H. Wessel, H. S. Park, and H. W. Roesky, "A sol-gel method using tetraethoxysilane and acetic anhydride: immobilization of cubic $\mu$-oxo Si-Ti complex in a silica matrix," Chemistry of Materials, vol. 14, no. 12, pp. 4975-4981, 2002.

[54] A. R. Oki, Q. Xu, B. Shpeizer et al., "Synthesis, characterization and activity in cyclohexene epoxidation of mesoporous $\mathrm{TiO}_{2}-\mathrm{SiO}_{2}$ mixed oxides," Catalysis Communications, vol. 8, no. 6, pp. 950-956, 2007.
[55] A. Matsuda, Y. Higashi, K. Tadanaga, and M. Tatsumisago, "Hot-water treatment of sol-gel derived $\mathrm{SiO}_{2}-\mathrm{TiO}_{2}$ microparticles and application to electrophoretic deposition for thick films," Journal of Materials Science, vol. 41, no. 24, pp. 8101-8108, 2006.

[56] J. W. Lee, S. Kong, W. S. Kim, and J. Kim, "Preparation and characterization of $\mathrm{SiO}_{2} / \mathrm{TiO}_{2}$ core-shell particles with controlled shell thickness," Materials Chemistry and Physics, vol. 106, no. 1, pp. 39-44, 2007.

[57] S. W. Lee, Y. U. Kim, S. S. Choi, T. Y. Park, Y. L. Joo, and S. G. Lee, "Preparation of $\mathrm{SiO}_{2} / \mathrm{TiO}_{2}$ composite fibers by sol-gel reaction and electrospinning," Materials Letters, vol. 61, no. 3, pp. 889-893, 2007.

[58] S. Zhan, D. Chen, X. Jiao, and Y. Song, "Mesoporous $\mathrm{TiO}_{2} / \mathrm{SiO}_{2}$ composite nanofibers with selective photocatalytic properties," Chemical Communications, no. 20, pp. 2043-2045, 2007.

[59] J. Jiao, Q. Xu, and L. Li, "Porous $\mathrm{TiO}_{2} / \mathrm{SiO}_{2}$ composite prepared using PEG as template direction reagent with assistance of supercritical $\mathrm{CO}_{2}$," Journal of Colloid and Interface Science, vol. 316, no. 2, pp. 596-603, 2007.

[60] H. Mori, Y. Miyamura, and T. Endo, "Synthesis and characterization of water-soluble $\mathrm{SiO}_{1.5} / \mathrm{TiO}_{2}$ hybrid nanoparticles by hydrolytic co-condensation of triethoxysilane containing hydroxyl groups," Materials Chemistry and Physics, vol. 115, no. 1, pp. 287-295, 2009.

[61] C. McCusker, J. B. Carroll, and V. M. Rotelo, "Cationic polyhedral oligomeric silsesquioxane (POSS) units as carriers for drug delivery processes," Chemical Communications, no. 8, pp. 996-998, 2005.

[62] L. Cui, D. Chen, and L. Zhu, "Conformation transformation determined by different self-assembled phases in a DNA complex with cationic polyhedral oligomeric silsesquioxane lipid," ACS Nano, vol. 2, no. 5, pp. 921-927, 2008.

[63] Q. C. Zou, Q. J. Yan, G. W. Song, S. L. Zhang, and L. M. Wu, "Detection of DNA using cationic polyhedral oligomeric silsesquioxane nanoparticles as the probe by resonance light scattering technique," Biosensors and Bioelectronics, vol. 22, no. 7, pp. 1461-1465, 2007.

[64] K. Y. Pu, K. Li, and B. Liu, "Cationic oligofluorenesubstituted polyhedral oligomeric silsesquioxane as lightharvesting unimolecular nanoparticle for fluorescence amplification in cellular imaging," Advanced Materials, vol. 22, no. 5, pp. 643-646, 2010.

[65] F. Zhao, C. Wan, X. Bao, and B. Kandasubramanian, "Modification of montmorillonite with aminopropylisooctyl polyhedral oligomeric silsequioxane," Journal of Colloid and Interface Science, vol. 333, no. 1, pp. 164-170, 2009.

[66] Y. C. Li, S. Mannen, J. Schulz, and J. C. Grunlan, "Growth and fire protection behavior of POSS-based multilayer thin films," Journal of Materials Chemistry, vol. 21, no. 9, pp. 3060-3069, 2011.

[67] H. Mori and M. Yamada, "Synthesis and characterization of cationic silsesquioxane hybrids by hydrolytic condensation of triethoxysilane derived from 2(dimethylamino)ethylacrylate," Colloid and Polymer Science. In press.

[68] A. Tuteja, W. Choi, M. Ma et al., "Designing superoleophobic surfaces," Science, vol. 318, no. 5856, pp. 1618-1622, 2007.

[69] J. M. Mabry, A. Vij, S. T. Iacono, and B. D. Viers, "Fluorinated polyhedral oligomeric silsesquioxanes (F-POSS)," Angewandte Chemie, vol. 47, no. 22, pp. 4137-4140, 2008.

[70] S. T. Iacono, A. Vij, W. Grabow, D. W. Smith Jr., and J. M. Mabry, "Facile synthesis of hydrophobic fluoroalkyl 
functionalized silsesquioxane nanostructures," Chemical Communications, no. 47, pp. 4992-4994, 2007.

[71] K. Koh, S. Sugiyama, T. Morinaga et al., "Precision synthesis of a fluorinated polyhedral oligomeric silsesquioxaneterminated polymer and surface characterization of its blend film with poly(methyl methacrylate)," Macromolecules, vol. 38, no. 4, pp. 1264-1270, 2005.

[72] Y. S. Ye, Y. C. Yen, W. Y. Chen, C. C. Cheng, and F. C. Chang, "A simple approach toward low-dielectric polyimide nanocomposites: blending the polyimide precursor with a fluorinated polyhedral oligomeric silsesquioxane," Journal of Polymer Science A, vol. 46, no. 18, pp. 6296-6304, 2008.

[73] I. Jerman, M. Koželj, and B. Orel, "The effect of polyhedral oligomeric silsesquioxane dispersant and low surface energy additives on spectrally selective paint coatings with selfcleaning properties," Solar Energy Materials and Solar Cells, vol. 94, no. 2, pp. 232-245, 2010.

[74] I. Jerman, B. Orel, A. S. Vuk, M. Koželj, and J. Kovač, "A structural and corrosion study of triethoxysilyl and perfluorooctyl functionalized polyhedral silsesquioxane nanocomposite films on AA 2024 alloy," Thin Solid Films, vol. 518, no. 10, pp. 2710-2721, 2010.

[75] S. T. Iacono, S. M. Budy, J. M. Mabry, and D. W. Smith Jr., "Synthesis, characterization, and surface morphology of pendant polyhedral oligomeric silsesquioxane perfluorocyclobutyl aryl ether copolymers," Macromolecules, vol. 40, no. 26, pp. 9517-9522, 2007.

[76] H. Hussain, B. H. Tan, C. S. Gudipati et al., "Synthesis and characterization of organic/inorganic hybrid star polymers of 2,2,3,4,4,4-hexafluorobutyl methacrylate and octa(aminophenyl)silsesquioxane nano-cage made via atom transfer radical polymerization," Journal of Polymer Science A, vol. 46, no. 22, pp. 7287-7298, 2008.

[77] H. Hussain, B. H. Tan, K. Y. Mya, Y. Liu, C. B. He, and T. P. Davis, "Synthesis, micelle formation and bulk properties of poly(ethylene glycol)b-poly(pentafluorostyrene)-gpolyhedral oligomeric silsesquioxane amphiphilic hybrid copolymers," Journal of Polymer Science A, vol. 48, no. 1, pp. 152-163, 2010.

[78] A. G. Kannan, N. R. Choudhury, and N. Dutta, "Fluorosilsesquioxane-urethane hybrid for thin film applications," ACS Applied Materials \& Interfaces, vol. 1, no. 2, pp. 336-347, 2009.

[79] H. Fujiwara, T. Narita, and H. Hamana, "Novel fluorinated hybrid polymer preparation from silsesquioxanes by radical polyaddition," Journal of Fluorine Chemistry, vol. 125, no. 9, pp. 1279-1285, 2004.

[80] S. T. Iacono, S. M. Budy, D. W. Smith, and J. M. Mabry, "Preparation of composite fluoropolymers with enhanced dewetting using fluorinated silsesquioxanes as drop-in modifiers," Journal of Materials Chemistry, vol. 20, no. 15, pp. 2979-2984, 2010.

[81] R. Misra, R. D. Cook, and S. E. Morgan, "Nonwetting, nonrolling, stain resistant polyhedral oligomeric silsesquioxane coated textiles," Journal of Applied Polymer Science, vol. 115, no. 4, pp. 2322-2331, 2010.

[82] K. Zeng and S. Zheng, "Nanostructures and surface dewettability of epoxy thermosets containing hepta(3,3,3trifluoropropyl) polyhedral oligomeric silsesquioxanecapped polyethylene oxide," Journal of Physical Chemistry B, vol. 111, no. 50, pp. 13919-13928, 2007.

[83] A. M. Douvas, F. Van Roey, M. Goethals et al., "Partially fluorinated, polyhedral oligomeric silsesquioxane-functionalized (meth)acrylate resists for $193 \mathrm{~nm}$ bilayer lithography," Chemistry of Materials, vol. 18, no. 17, pp. 4040-4048, 2006.

[84] C. Pina-Hernandez, P. F. Fu, and L. J. Guo, "Easy duplication of stamps using UV-cured fluoro-silsesquioxane for nanoimprint lithography," Journal of Vacuum Science and Technology B, vol. 26, no. 6, pp. 2426-2429, 2008.

[85] H. Mori, C. Sada, T. Konno, and K. Yonetake, "Synthesis and characterization of low-refractive-index fluorinated silsesquioxane-based hybrids," Polymer, vol. 52, pp. 54525463, 2011.

[86] Y. C. Sheen, C. H. Lu, C. F. Huang, S. W. Kuo, and F. C. Chang, "Synthesis and characterization of amorphous octakis-functionalized polyhedral oligomeric silsesquioxanes for polymer nanocomposites," Polymer, vol. 49, no. 18, pp. 4017-4024, 2008.

[87] R. M. Laine and M. F. Roll, "Polyhedral phenylsilsesquioxanes," Macromolecules, vol. 44, no. 5, pp. 1073-1109, 2011.

[88] C. Liu, Y. Liu, Z. Shen, P. Xie, D. Dai, R. Zhang et al., "Synthesis and characterization of novel alcohol-soluble ladderlike poly(silsesquioxane)s containing side-chain hydroxy groups," Macromolecular Chemistry and Physics, vol. 202, pp. 1576-1580, 2001.

[89] K. Zeng, L. Wang, S. Zheng, and X. Qian, "Self-assembly behavior of hepta(3,3,3-trifluoropropyl) polyhedral oligomeric silsesquioxane-capped poly( $\varepsilon$-caprolactone) in epoxy resin: nanostructures and surface properties," Polymer, vol. 50, no. 2, pp. 685-695, 2009.

[90] K. Zeng, Y. Liu, and S. Zheng, "Poly(ethylene imine) hybrids containing polyhedral oligomeric silsesquioxanes: preparation, structure and properties," European Polymer Journal, vol. 44, no. 12, pp. 3946-3956, 2008.

[91] K. Zeng and S. Zheng, "Synthesis and characterization of organic/inorganic Polyrotaxanes from Polyhedral oligomeric silsesquioxane and poly(ethylene oxide) $/ \alpha$ - cyclodextrin polypseudorotaxanes via click chemistry," Macromolecular Chemistry and Physics, vol. 210, no. 9, pp. 783-791, 2009.

[92] H. Mori, C. Sada, T. Konno, R. Koizumi, and K. Yonetake, "Film-forming amphiphilic silsesquioxane hybrids prepared by hydrolytic co-condensation of hydroxyl-functionalized and fluorinated triethoxysilanes," Polymer, vol. 53, pp. 3849-3860, 2012.

[93] J. Rodríguez-Hernández, F. Chécot, Y. Gnanou, and S. Lecommandoux, "Toward 'smart' nano-objects by selfassembly of block copolymers in solution," Progress in Polymer Science, vol. 30, no. 7, pp. 691-724, 2005.

[94] H. Mori and A. H. E. Müller, "New polymeric architectures with (meth)acrylic acid segments," Progress in Polymer Science, vol. 28, no. 10, pp. 1403-1439, 2003.

[95] S. Förster, V. Abetz, and A. H. E. Müller, "Polyelectrolyte block copolymer micelles," Advances in Polymer Science, vol. 166, pp. 173-210, 2004.

[96] A. O. Moughton and R. K. O’Reilly, "Using metallosupramolecular block copolymers for the synthesis of higher order nanostructured assemblies," Macromolecular Rapid Communications, vol. 31, no. 1, pp. 37-52, 2010.

[97] H. Mori, M. G. Lanzendörfer, A. H. E. Müller, and J. E. Klee, "Organic-inorganic nanoassembly based on complexation of cationic silica nanoparticles and weak anionic polyelectrolytes in aqueous and alcohol media," Langmuir, vol. 20, no. 5, pp. 1934-1944, 2004.

[98] A. K. Boal, F. Ilhan, J. E. Derouchey, T. Thurn-Albrecht, T. P. Russell, and V. M. Rotello, "Self-assembly of nanoparticles into structured spherical and network aggregates," Nature, vol. 404, no. 6779, pp. 746-748, 2000. 
[99] B. L. Frankamp, O. Uzun, F. Ilhan, A. K. Boal, and V. M. Rotello, "Recognition-mediated assembly of nanoparticles into micellar structures with diblock copolymers," Journal of the American Chemical Society, vol. 124, no. 6, pp. 892-893, 2002.

[100] M. Hara, J. T. Lean, and T. E. Mallouk, "Photocatalytic oxidation of water by silica-supported tris $\left(4,4^{\prime}\right.$-dialkyl-2,2' bipyridyl)ruthenium polymeric sensitizers and colloidal iridium oxide," Chemistry of Materials, vol. 13, no. 12, pp. 4668-4675, 2001.

[101] R. Tamaki and Y. Chujo, "Synthesis of polystyrene and silica gel polymer hybrids utilizing ionic interactions," Chemistry of Materials, vol. 11, no. 7, pp. 1719-1726, 1999.

[102] A. R. Bassindale, A. Codina-Barrios, N. Frascione, and P. G. Taylor, "The use of silsesquioxane cages and phage display technology to probe silicone-protein interactions," New Journal of Chemistry, vol. 32, no. 2, pp. 240-246, 2008.

[103] N. Alobaid, H. J. Salacinski, K. M. Sales et al., "Nanocomposite containing bioactive peptides promote endothelialisation by circulating progenitor cells: an in vitro evaluation," European Journal of Vascular and Endovascular Surgery, vol. 32, no. 1, pp. 76-83, 2006.

[104] A. De Mel, G. Punshon, B. Ramesh et al., "In situ endothelialisation potential of a biofunctionalised nanocomposite biomaterial-based small diameter bypass graft," Bio-Medical Materials and Engineering, vol. 19, no. 4-5, pp. 317-331, 2009.

[105] T. L. Kaneshiro, X. Wang, and Z. R. Lu, "Synthesis, characterization, and gene delivery of poly-L-iysine octa(3aminopropyl)silsesquioxane dendrimers: nanoglobular drug carriers with precisely defined molecular architectures," Molecular Pharmaceutics, vol. 4, no. 5, pp. 759-768, 2007.

[106] T. L. Kaneshiro and Z. R. Lu, "Targeted intracellular codelivery of chemotherapeutics and nucleic acid with a well-defined dendrimer-based nanoglobular carrier," Biomaterials, vol. 30, no. 29, pp. 5660-5666, 2009.

[107] S. W. Kuo, H. F. Lee, W. J. Huang, K. U. Jeong, and F. C. Chang, "Solid state and solution self-assembly of helical polypeptides tethered to polyhedral oligomeric silsesquioxanes," Macromolecules, vol. 42, no. 5, pp. 1619-1626, 2009.

[108] S. W. Kuo and H. T. Tsai, "Control of peptide secondary structure on star shape polypeptides tethered to polyhedral oligomeric silsesquioxane nanoparticle through click chemistry," Polymer, vol. 51, no. 24, pp. 5695-5704, 2010.

[109] S. Fabritz, D. Heyl, V. Bagutski et al., "Towards click bioconjugations on cube-octameric silsesquioxane scaffolds," Organic \& Biomolecular Chemistry, vol. 8, no. 9, pp. 22122218, 2010.

[110] H. Mori and T. Endo, "Amino acid-based block copolymers by RAFT polymerization," Macromolecular Rapid Communications, vol. 33, pp. 1090-1107, 2012.

[111] H. Mori and S. Saito, "Smart organic-inorganic hybrids based on the complexation of amino acid-based polymers and water-soluble silsesquioxane nanoparticles," Reactive and Functional Polymers, vol. 71, no. 10, pp. 1023-1032, 2011.

[112] H. Mori, I. Kato, M. Matsuyama, and T. Endo, "RAFT polymerization of acrylamides containing proline and hydroxyproline moiety: controlled synthesis of water-soluble and thermoresponsive polymers," Macromolecules, vol. 41, no. 15 , pp. 5604-5615, 2008.

[113] H. Mori, H. Iwaya, A. Nagai, and T. Endo, "Controlled synthesis of thermoresponsive polymers derived from L-proline via RAFT polymerization," Chemical Communications, no. 38, pp. 4872-4874, 2005.
[114] H. Mori, H. Iwaya, and T. Endo, "Controlled synthesis of thermoresponsive polymer via RAFT polymerization of an acrylamide containing l-proline moiety," Reactive and Functional Polymers, vol. 67, no. 10, pp. 916-927, 2007.

[115] H. Mori, H. Iwaya, and T. Endo, "Structures and chiroptical properties of thermoresponsive block copolymers containing L-proline moieties," Macromolecular Chemistry and Physics, vol. 208, no. 17, pp. 1908-1918, 2007.

[116] S. Luo, J. Xu, Y. Zhang, S. Liu, and C. Wu, "Double hydrophilic block copolymer monolayer protected hybrid gold nanoparticles and their shell cross-linking," Journal of Physical Chemistry B, vol. 109, no. 47, pp. 22159-22166, 2005.

[117] B. J. Kim, J. J. Chiu, G. R. Yi, D. J. Pine, and E. J. Kramer, "Nanoparticle-induced phase transitions in diblockcopolymer films," Advanced Materials, vol. 17, no. 21, pp. 2618-2622, 2005.

[118] Y. Kang and T. A. Taton, "Controlling shell thickness in coreshell gold nanoparticles via surface-templated adsorption of block copolymer surfactants," Macromolecules, vol. 38, no. 14, pp. 6115-6121, 2005.

[119] B. S. Kim and T. A. Taton, "Multicomponent nanoparticles via self-assembly with cross-linked block copolymer surfactants," Langmuir, vol. 23, no. 4, pp. 2198-2202, 2007.

[120] Y. Kang and T. A. Taton, "Core/shell gold nanoparticles by self-assembly and crosslinking of micellar, block-copolymer shells," Angewandte Chemie, vol. 44, no. 3, pp. 409-412, 2005.

[121] H. Mori, S. Saito, and K. Shoji, "Complexation of aminoacid-based block copolymers with dual-thermoresponsive properties and water-soluble silsesquioxane nanoparticles," Macromolecular Chemistry and Physics, vol. 212, pp. 25582572, 2011. 

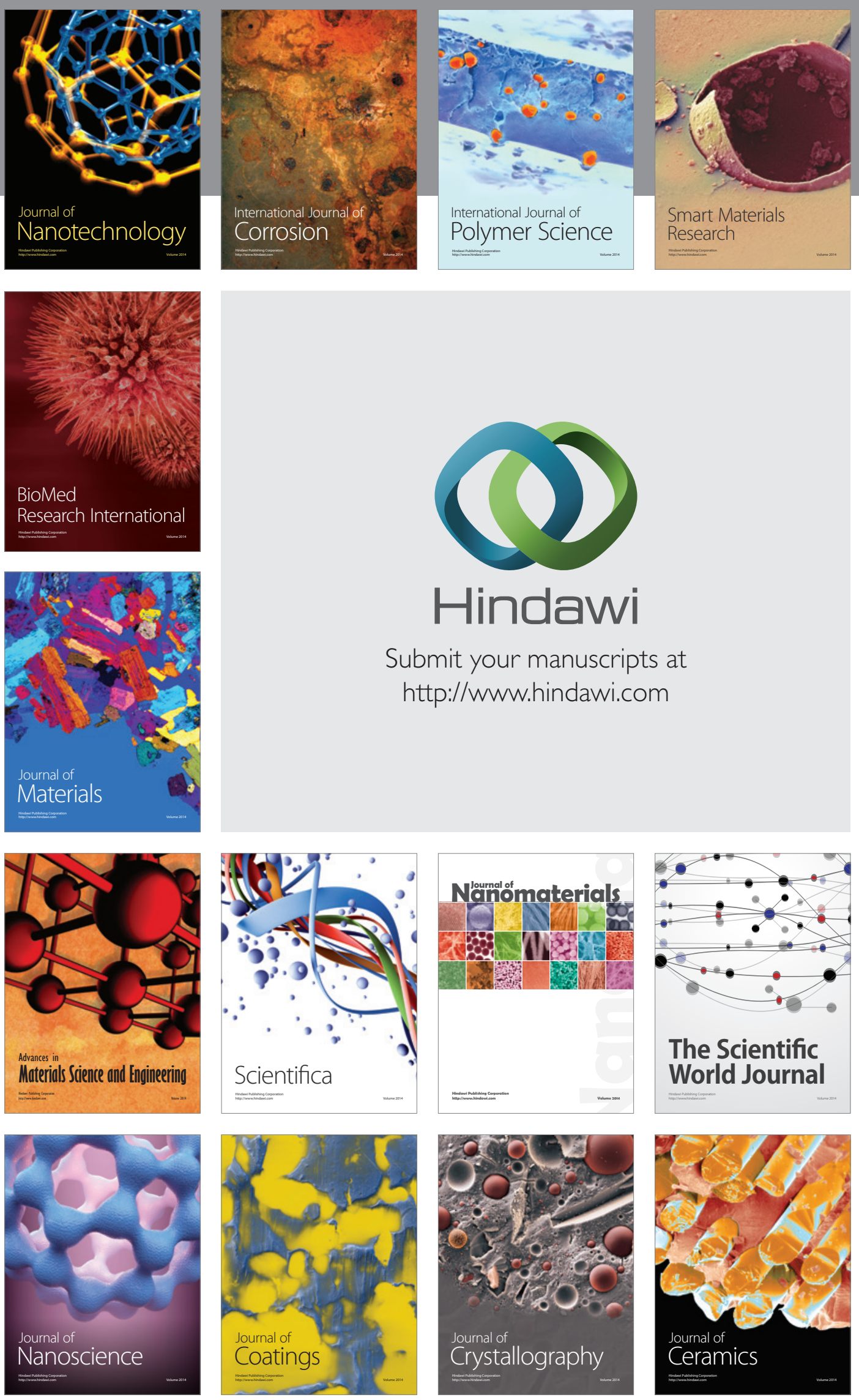

The Scientific World Journal

Submit your manuscripts at

http://www.hindawi.com

\section{World Journal}

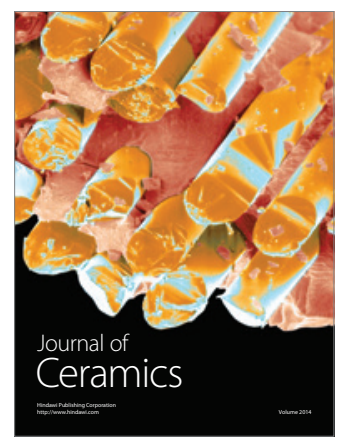

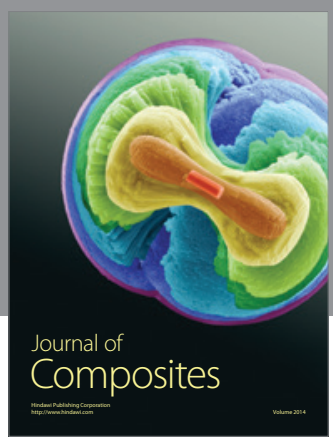
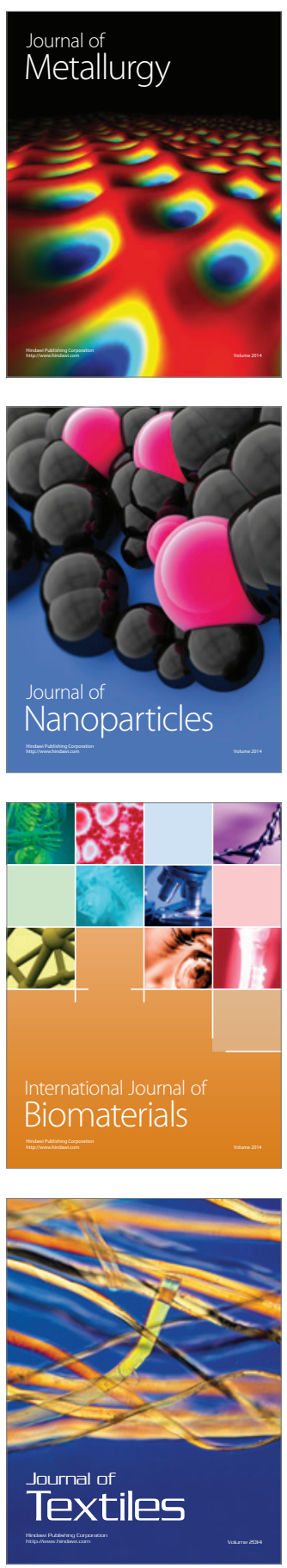